\title{
THE RELATIONSHIP OF OCCUPATIONAL STRESS, PSYCHOLOGICAL STRAIN, AND COPING RESOURCES TO THE TURNOVER INTENTIONS OF REHABILITATION COUNSELORS
}

\author{
by \\ Christina Mann Layne \\ Virginia Polytechnic Institute and State University \\ Dissertation submitted to the Faculty of the \\ Virginia Polytechnic Institute and State University \\ in partial fulfillment of the requirements for the degree of
}

DOCTOR OF PHILOSOPHY

in

COUNSELOR EDUCATION

Committee:

Thomas H. Hohenshil, Co-Chair

Kusum Singh, Co-Chair

Hildy Getz

James Garrison

Fred Capps

October 15, 2001

Blacksburg, Virginia

Key Words: Strain, Coping, Turnover, Occupational Stress, Rehabilitation Counselors 


\section{THE RELATIONSHIP OF OCCUPATIONAL STRESS, PSYCHOLOGICAL STRAIN, AND COPING RESOURCES TO THE TURNOVER INTENTIONS OF REHABILITATION COUNSELORS \\ by \\ Christina Mann Layne \\ Thomas H. Hohenshil \& Kusum Singh, Co-Chairs \\ Counselor Education}

\section{(ABSTRACT)}

The Occupational Stress Inventory Revised Edition (OSI-R) and an Individual Data Form were used to determine the turnover intentions of rehabilitation counselors based on an interactive model of stress, strain, and coping. Occupational stress, strain, coping resources, and turnover intentions were examined in relationship with various demographic variables collected from a national sample of 982 members of the American Rehabilitation Counselors Association (ARCA). Demographic variables included age, gender, ethnicity, certification status as a Certified Rehabilitation Counselor (CRC), years of experience, practice setting, the number of clients on a counselor's caseload, and the amount of hours worked per week.

Data were collected through a mail survey, with a response rate of $67 \%(\mathrm{~N}=657)$. However, of those respondents only $22 \%(\mathrm{~N}=145)$ had complete data and met the inclusion criteria. Inclusion criterion consisted of considering oneself to be employed full-time as a practicing rehabilitation counselor. Based on the usable data $(\mathrm{N}=145)$, respondents were on average 44 years old and Caucasian, with $63 \%$ being female. Over half of the respondents were certified as rehabilitation counselors, with an average number of nine years of certification. The average number of years of experience as a rehabilitation counselor was approximately ten and respondents worked an average of 45 hours per week with an average caseload size of 88 clients.

Path analysis was used to analyze causal relationships among turnover related variables. The hypothesized model included age, experience, number of clients on a caseload, occupational stress, strain, coping resources, and turnover intention. The tested model explained $37.5 \%$ of the variance in turnover intentions. The results suggest that the turnover intentions of rehabilitation counselors is meaningfully accounted for by variables contained in the model. Occupational stress produced the largest significant effect $(\mathrm{B}=.404)$ and had the most influence on turnover intentions. This indicates that it is occupational stress inherent in the job functions of rehabilitation counselors, and not individual coping resources or demographic variables that account for turnover in the field of rehabilitation. Therefore rehabilitation agencies should examine the roles that they place rehabilitation counselors in versus the individual characteristics of rehabilitation counselors in order to reduce turnover in the field. 


\section{ACKNOWLEDGMENTS}

As this adventure on my journey of life comes to an end and another one begins, I would like to thank the following individuals:

Dr. Hohenshil - for his patience and guidance, as well as for being able to tolerate endless trips to the Higher Education Center in Roanoke with me.

Dr. Singh - for letting me ask really unintelligent questions with out laughing at me and for making me learn more than I ever wanted to about statistics.

Dr. Capps, Dr. Garrison, and Dr. Getz - for offering me good suggestions and making the process such a pleasant experience from the beginning.

Abrina and Katherine - for reminding me that the most important things in life can be found in the smiles of newborns. Abrina - for also being my mentor and true friend from the moment we met.

Sara - for her unconditional friendship, encouragement, and for all of the hundreds of little things she has done to make me smile.

Justin - for endless hours at expresso, long gripping sessions, and for always being there when I really needed him.

Tim - for his long distance friendship, statistical advice, and Monday nights.

Cathy - for hours of paper shuffling, envelop stuffing, and giving me the reframe "B or better."

Bill - for supporting his wife in spending her free time helping me and teaching me the art of jagering as a couple.

My mother-in-law and brothers-in-law - for putting up with me and supporting their son/brother in marrying an independent, outspoken woman from New York.

My mother - for her patience and Rogerian approach to counseling me through tough times.

My father - for pushing me to be better than I was and reminding me always that "its never over "til its over."

My husband - for traveling with me through the hills and valleys. For his silent suffering while I spent every spare moment studying or writing. Kiam taught me the most important lesson I learned, and that is to always be positive and smile in the face of adversity.

Finally, I would like to dedicate my dissertation to my sisters, all of whom make me proud in their own special ways. K.J., may all of your dreams come true. With hard work and perseverance you can do anything. Heather, may you find what you are searching for and find some happiness along the way. Melissa, may you continue to take life less seriously, remember to laugh at yourself (and me) as often as possible. Happiness will never be found in how much money you make or the title you possess. 


\section{TABLE OF CONTENTS}

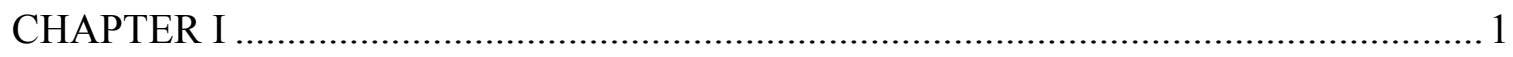

INTRODUCTION

Rationale

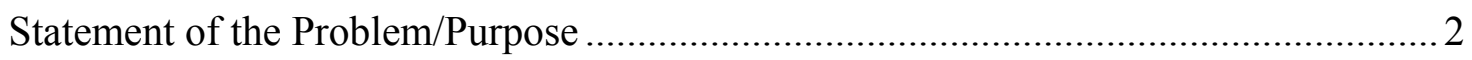

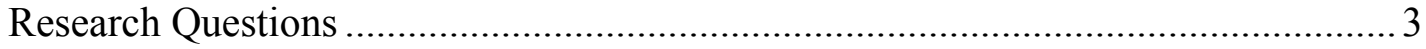

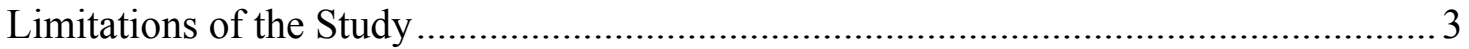

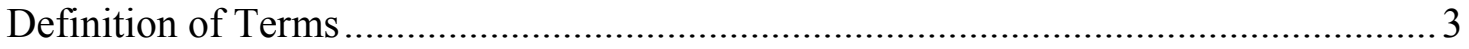

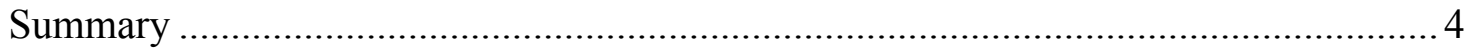

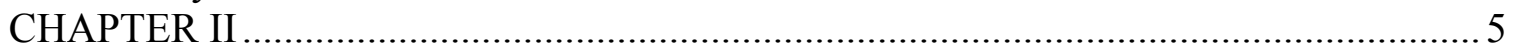

LITERATURE REVIEW ……………………………..................................

Turnover Intentions: Review and Relationship to Burnout and the OSI-R .................. 5

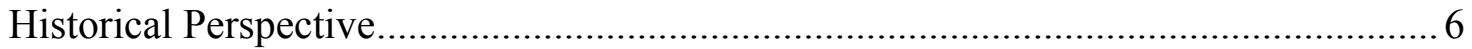

Theoretical Approaches to the Relationships Between Stress, Strain, and Coping ........ 7

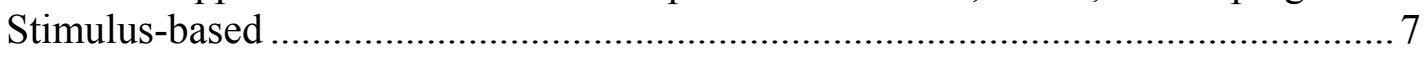

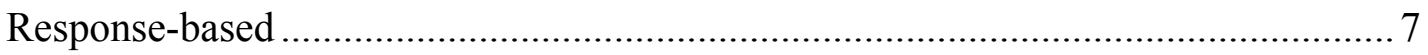

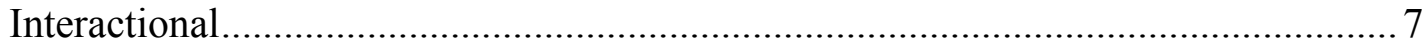

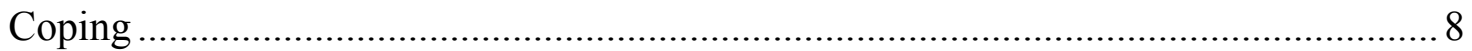

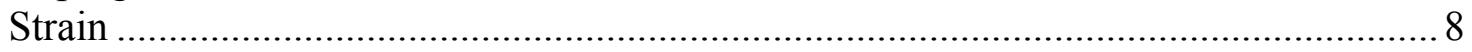

Coping as a Mediating Variable for Strain: Perception and Appraisal ........................... 8

Occupational Stress: Relevant Theoretical Issues........................................................ 9

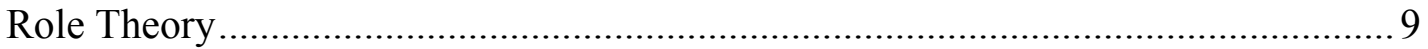

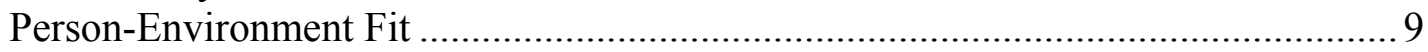

Rehabilitation Counselors and Occupational Stress................................................. 10

Occupational Stress Inventory Revised Edition (OSI-R)............................................ 10

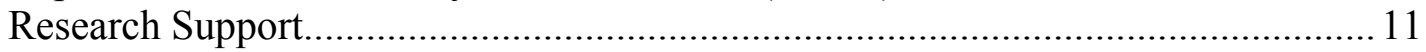

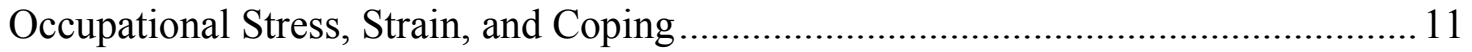

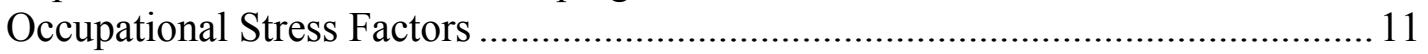

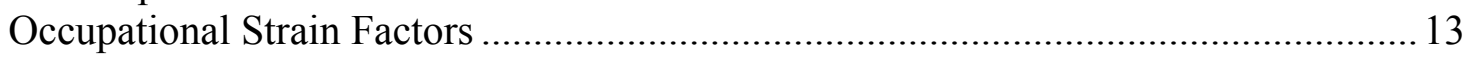

Occupational Coping Factors ................................................................................ 14

Correlates of Occupational Stress, Strain, and Coping ................................................. 16

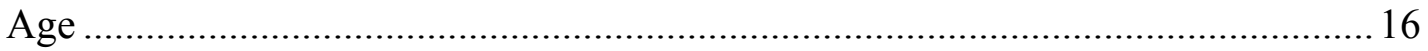

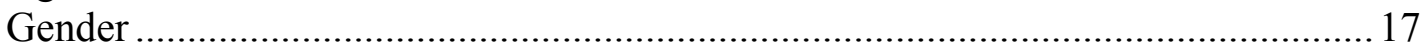

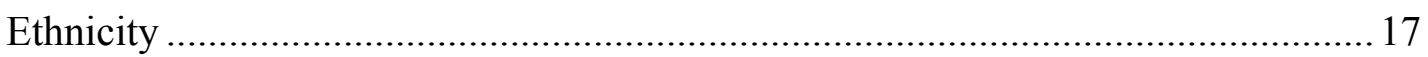

Certification Status as a Rehabilitation Counselor.................................................... 17

Experience: Number of Years in the Profession .................................................... 18

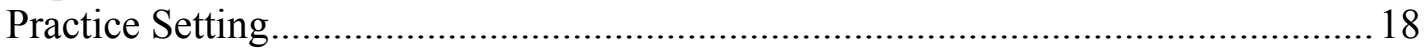

Average Number of Clients on Caseload ............................................................... 19

Average Number of Hours Worked Per Week........................................................ 19

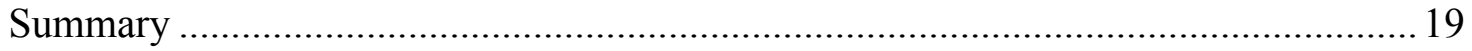

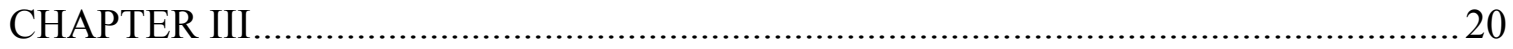

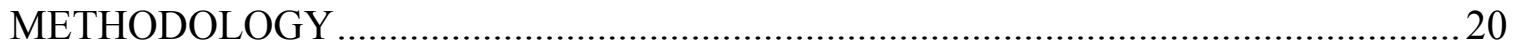




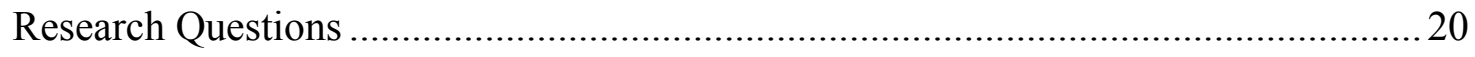

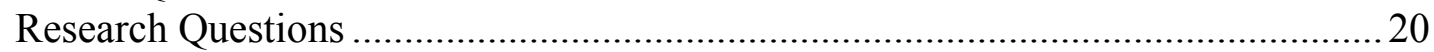

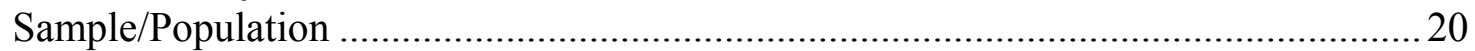

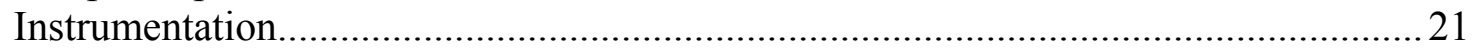

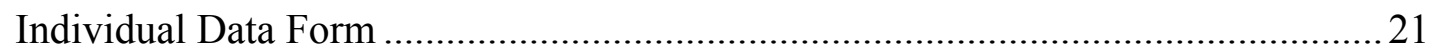

The Occupational Stress Inventory Revised Edition.................................................2 21

Data Collection Process .......................................................................................22

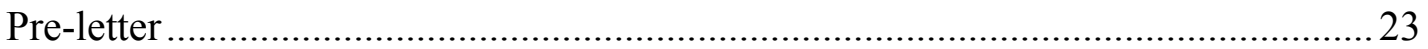

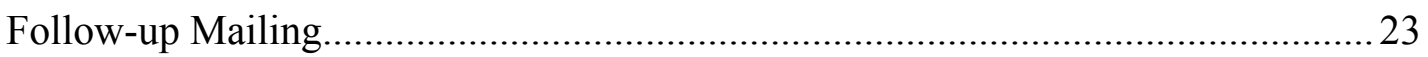

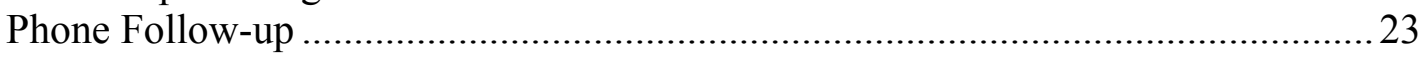

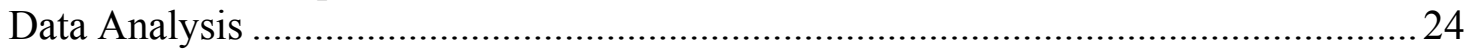

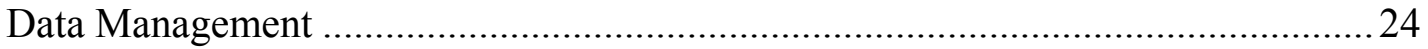

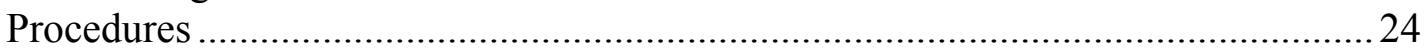

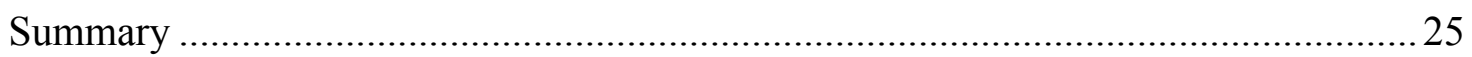

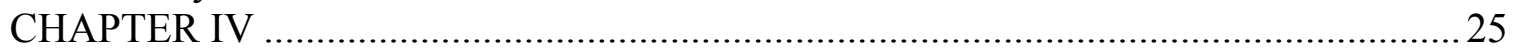

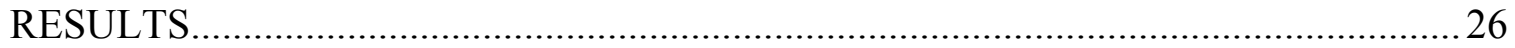

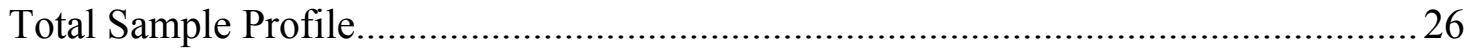

Descriptive Statistics and Correlations for Demographic Variables............................. 26

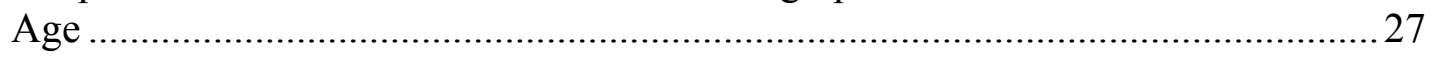

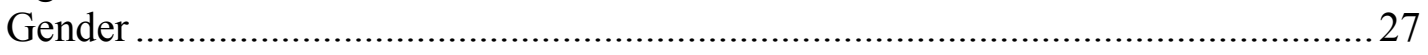

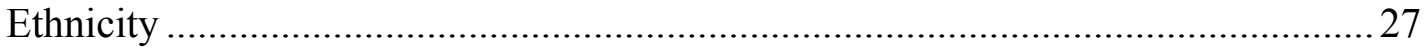

Certification Status as a Rehabilitation Counselor...................................................2

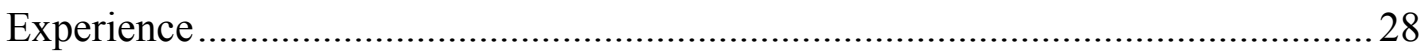

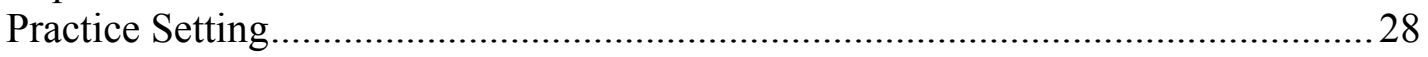

Average Number of Clients on Caseload ........................................................... 28

Average Number of Hours Worked Per Week....................................................... 28

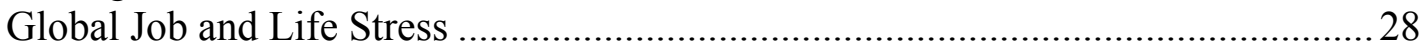

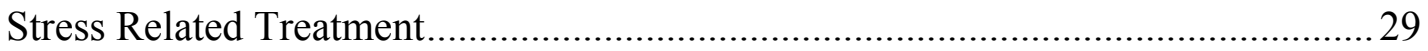

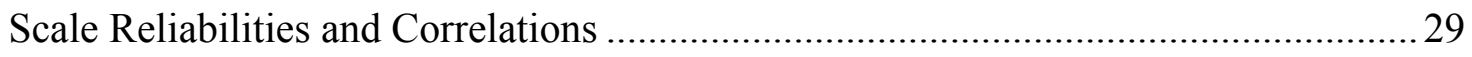

Correlation Matrix for Turnover, Stress, Strain, and Coping..................................... 30

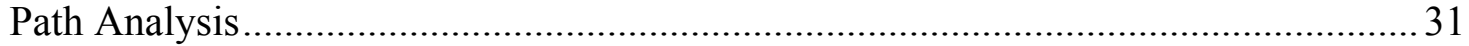

Effect of Strain on Turnover Intentions ..................................................................... 33

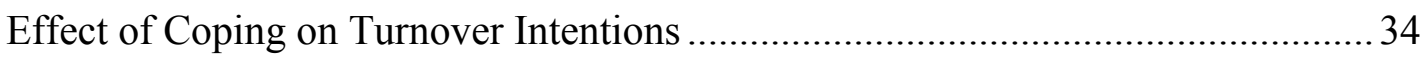

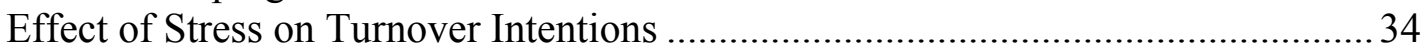

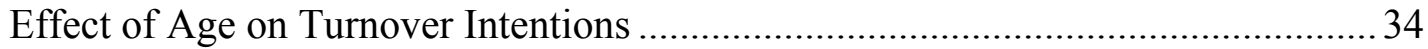

Effect of Experience on Turnover Intentions ............................................................. 34

Effect of Number of Clients on Caseload on Turnover Intentions ............................. 34

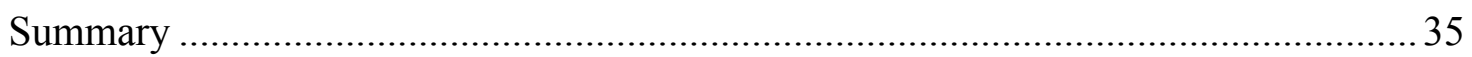

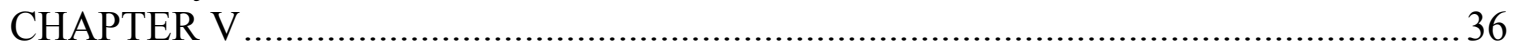

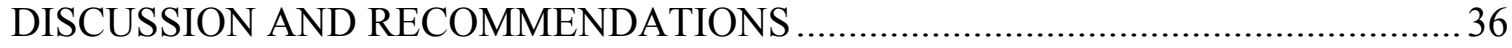

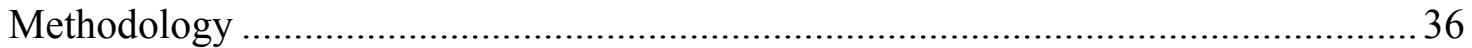

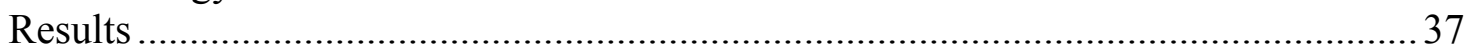

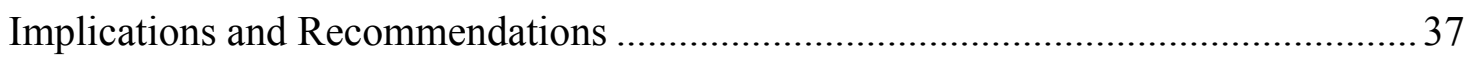

Recommendations for Practicing Professionals ......................................................... 37

Recommendations for Rehabilitation Training Programs.......................................... 39

Recommendations for Future Research .................................................................. 40 


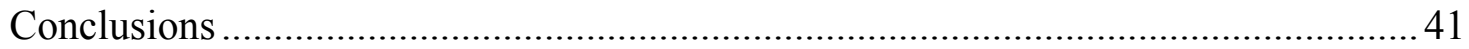

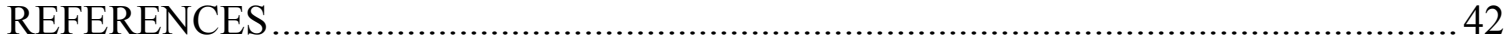

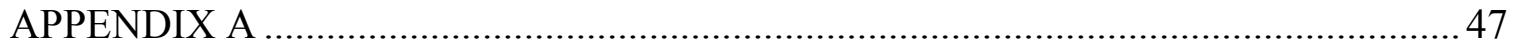

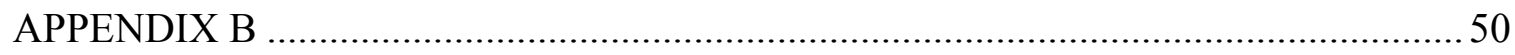

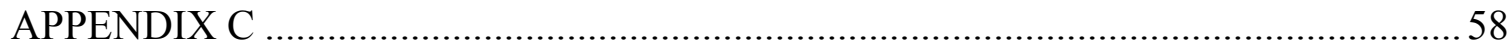

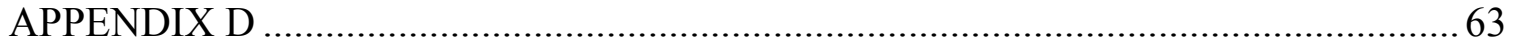




\section{LIST OF TABLES}

TABLE 1.0 Correlation Matrix for Turnover, Stress, Strain, and Coping....................... 30

TABLE 2.0 Direct, Indirect, and Total Effects of Age, the Number of Clients on a Caseload, Stress, Strain, and Coping Resources on the Turnover Intentions of Rehabilitation Counselors .......................... 33 


\section{LIST OF FIGURES}

FIGURE 1.0 Path Analysis of the Hypothesized Relationship Between

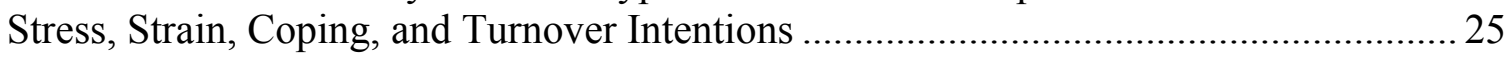

FIGURE 2.0 Hypothesized Model of Turnover Intentions.............................................. 32

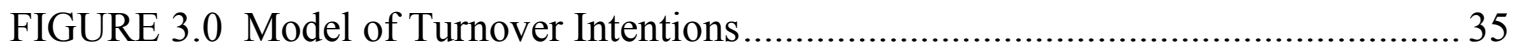




\section{CHAPTER I}

\section{INTRODUCTION}

The rehabilitation counseling profession has a long history of serving persons with disabilities as they work toward achieving their individual goals. Rehabilitation counselors serve as advocates and sources of support for persons who may not be able to negotiate the complicated and ever increasing system of resources that is available. As advocates that serve traditionally neglected populations, they have a well-documented history of high job turnover (Barrett, Riggar, Flowers, Crimando, \& Bailey, 1997; Crimando, Riggar, \& Hansen, 1986; Razza, 1993) and little job satisfaction (Barrett et al., 1997; Riggar, Hansen, \& Crimando, 1987). Despite this, there are few significant studies that have been interested in professionals in rehabilitation; instead the primary focus has been on the clients (Garske, 1996).

Occupations in the field of human services "are considered to be high stress occupations, dealing with pervasive social as well as individual problems" (Garske, 1999, p. 21). Stress associated with rehabilitation counseling stems from a wide variety of external and internal sources. In one study of rehabilitation counselors it was reported that the aspects of the occupation that were disliked the most were dealing with bureaucracies, regulations, restrictions, and excessive amounts of paperwork (Garske, 1999). Other aspects of the occupation that were reported to be aversive included funding resource problems (Garske, 1999), organizational politics (Farber \& Heifetz, 1982), high counselor per client ratios (Flett \& Biggs, 1992), and caseload size (Garske, 1999). To further compound matters; access to community resources may be difficult, there might be an increased necessity for advocacy on the part of the counselor in conjunction with having to contend with intensive client needs (psychological and physical), emotional demands from clients (Shinn et al., 1984) or working with unmotivated or difficult clients (Garske, 1999) as well as a decreased perceived worth of persons with disabilities by society. In addition, high turnover, low job satisfaction, and high job availability inevitably translates into less educated and under-trained individuals assuming occupational roles that may be beyond their capabilities (Barrett et al., 1997). Finally, individuals may be moving up the ranks faster into administrative positions in order to account for staff shortages. This translates into a majority of today's rehabilitation administrators having sparse or a complete lack of education or training concerning management and administration (Barrett et al., 1997).

Literature in the field of rehabilitation counseling supports and has made numerous attempts to examine high burnout rates (Bloom, Buhrke, \& Scott, 1988; Day \& Chambers, 1991; Garske, 1996; Razza, 1993). The stress that either results in burnout or causes burnout is also associated with various physiological and psychiatric disorders (Kahill, 1988). However, much less is known about where exactly this stress originates (Biggs, Flett, Voges, \& Alpass, 1995). Consequently, although burnout is not the only factor of turnover, Razza (1993) addresses it as a likely determinate factor. Turnover is a detrimental problem in the field of rehabilitation, with the cost of personnel turnover per rehabilitation facility estimated to be $\$ 164,908$ per year (Barrett et al., 1997). Due to the potential for stress to develop among rehabilitation counselors, this research study will also examine whether rehabilitation counselors are using coping resources in practice as well as whether there is an existing relationship between stress, strain, coping, and turnover intentions.

\section{Rationale}

In the United States, the field of rehabilitation has a "long and distinguished history ... with nearly 35 years of progress and accomplishments” (Leahy \& Szymanski, 1995, p. 165). 
The ability of rehabilitation counselors to function under a plethora of imposed internal and external constraints produces stress resulting in burnout at a high rate that is well documented in the human service arena (Garske, 1999). However, the research of Cranswick (1997) is indicative of the fact "that the work experiences of rehabilitation workers are unique and not necessarily the same as other human service workers" (p. 131). "Specific and extensive knowledge is needed to work effectively with specialized populations" (Havranek \& Brodwin, 1994, p. 369). Havranek and Brodwin (1994) examined role and function studies and found that "there is strong evidence that the profession is distinct and different than other counseling areas" (p. 370).

Rehabilitation counselors tend to work as members of interdisciplinary teams, often coordinating services for an individual between agencies in the community or within several interagency departments. Individuals with whom a rehabilitation counselor will be in contact regarding coordination of services include but are not limited to: (a) psychologists, (b) psychiatrists (c) social services agency representatives, (d) family members, (e) physical therapists, (f) occupational therapists, (g) social workers, (h) administrators, (i) speech pathologists, and (j) other mental health professionals. While decreased job satisfaction and high turnover rates have been well documented, it is important to establish the variables responsible for potential psychological stress associated with specific work roles.

With the continuing trend toward high turnover in the field of rehabilitation counseling (Barrett et al., 1997) it is imperative to rehabilitation counselors and the clients they serve to identify factors associated with occupational stress and its relationship to turnover intentions. This information is applicable to the following populations: (a) counseling students interested in pursuing a career in rehabilitation counseling, (b) current rehabilitation counselors, (c) rehabilitation administrators, (d) counselor educators, and (e) other researchers in the field. Results of this study have direct implications for the potential directions of future research endeavors that might serve to expand our current knowledge of occupational stress, psychological strain, and coping in rehabilitation counselors.

Statement of the Problem/Purpose

Stress affects individuals not only psychologically, by manifesting as anxiety or depression (McGuigan, 1999), but also physically. Physical stress symptoms include "anything from ulcers and digestive upsets to coronary problems" (Minirth, Hawkins, Meier, \& Flournoy, 1986, p. 16). Stress also interacts negatively with job satisfaction (Jex, 1998), performance (Jex, 1998; McGuigan, 1999), and commitment (Jex, 1998). Stress and its' impact upon occupational functioning is a major factor in reduced productivity (Glasser, 1984; McGuigan, 1999).

It is important to have a clear understanding of the types of psychological stress and subsequent strain that are contributing to high turnover rates (Barrett et al., 1997) which have plagued the field of rehabilitation since its' conception. While there are a plethora of studies that address the issues of burnout and job satisfaction in rehabilitation counseling, there are very few that look at turnover (Barrett et al., 1997). There is also a lack of research in the recent years regarding the amount of occupational stress and coping resources of rehabilitation counselors (Biggs et al., 1995). This study is primarily interested in how stress, strain, and coping directly and indirectly affect turnover intentions of rehabilitation counselors. The main hypothesis is that stress has direct effects on turnover intentions but also indirect effects through strain and coping resources. This study also looks at the relationships between stress, strain, and coping resources, as well as how all three affect turnover intentions. Of secondary interest are the relationships 
between stress, strain, coping resources, turnover intentions, and various demographic variables. The following questions are proposed in order to address the aforementioned problems:

\section{Research Questions}

1. What are the effects of stress, strain, and coping on the turnover intentions of rehabilitation counselors? More specific questions are:

a. What is the direct effect of stress on turnover intentions?

b. What is the indirect effect of stress mediated by coping and strain on turnover intentions?

c. What is the direct effect of stress on coping?

d. What is the direct effect of stress on strain?

e. What is the indirect effect of coping mediated by strain on turnover intentions?

f. What is the direct effect of strain on turnover intentions?

In addition, differences in occupational stress, strain, and coping factors for rehabilitation counselors are examined based on the following demographic variables: (a) age, (b) gender, (c) ethnicity, (d) certification status as a rehabilitation counselor, (e) number of years in the profession, (f) practice setting, (g) average number of clients per caseload, and (h) hours worked per week.

\section{Limitations of the Study}

This sample consists of rehabilitation counselors that belong to the American Rehabilitation Counselors Association (ARCA) and are employed full time primarily as rehabilitation counselors. Global generalization of results to individuals that work in the rehabilitation field, but do not belong to this professional association, presents a problem. Participation in a professional association, may in and of itself systematically affect the variables of interest. In addition, it would be impossible to conduct an environmental assessment of each participant's job site. As mentioned in a study that utilized the OSI, "such an assessment would have provided a more behavioral assessment of subjects' lives at work and the stresses to which they may have been subject"(Decker \& Borgen, 1993, p. 477). Therefore these results should not be fully generalized to all rehabilitation counselors, but cautious generalizations about the effects of stress, strain, and coping on turnover in the field can be made.

\section{Definition of Terms}

Although the definitions of terms are fairly standard in the field, for the purposes of this study the following definitions have been operationalized and references have been provided: Rehabilitation Counselor - counselors who designate the field of "rehabilitation counseling" as their primary area of work and are also members of the ARCA.

Occupational Stress - Stresses inherent and associated with various work roles. The OSI-R uses the Occupational Role Questionnaire (ORQ) to measure six stress-inducing work roles: (a) role overload, (b) role insufficiency, (c) role ambiguity, (d) role boundary, (e) responsibility, and (f) physical environment (Osipow, 1998).

$\underline{\text { Strain }}$ - Strains are the behavioral, physiological, and psychological processes that occur under the influence of stress and disrupt normal functioning (Winnubst, 1993). The OSI-R uses the Personal Strain Questionnaire (PSQ) to identify strain and categorize it into one of the following four groups: (a) psychological, (b) physical, (c) interpersonal, and (d) vocational (Osipow, 1998). Coping - Psychological and physical resources used to counter the effects of occupational stress. The OSI-R uses the Personal Resources Questionnaire (PRQ) in which four categories of coping behaviors have been identified: (a) self-care behavior, emphasizing engagement in healthy activities; (b) social support systems, emphasizing relationships with family and friends as well 
as social groups; (c) cognitive skills, focusing on the ability to reduce stress through the effective management of time and effort; and (d) recreational activities, serving as a distraction from stressful events and as a source of life satisfaction outside of the work setting (Osipow, 1998).

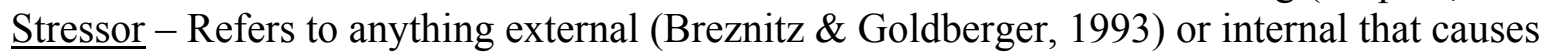
stress either psychologically or physiologically (McEwen \& Mendelson, 1993).

Turnover - Refers to the phenomena of individuals voluntarily quitting or resigning from an organization (Mobley, 1977; Price, 1977).

Turnover Intention - Refers to the intention of individuals to voluntarily quit or resign from an organization.

\section{Summary}

The purpose of this chapter was to provide an overview of this study. The research questions have been clearly delineated in order to address the problem at hand related to the occupational stress, psychological strain, and coping resources of rehabilitation counselors and the subsequent relationship to turnover intentions in the field. Finally, definitions of terms have been operationalized and limitations of the study have been outlined. 


\section{CHAPTER II}

\section{LITERATURE REVIEW}

This chapter presents an overview of the literature, both research based and theoretical, as it relates to the constructs of occupational stress, psychological strain, and coping resources of rehabilitation counselors, as well as the subsequent relationship to turnover intentions in the field of rehabilitation.

Turnover Intentions: Review and Relationship to Burnout and the OSI-R

There is a plethora of research regarding turnover beginning in the 1900's. Turnover has been defined as "the degree of individual movement across the membership boundary of a social system"(Price, 1977, p. 4). However, as of 1987 there had been no studies conducted regarding rehabilitation employee turnover (Riggar et al., 1987). This is surprising since "it is clear that considerable money, time, and effort are lost each year in rehabilitation because of workers who can no longer function or cope successfully in their jobs" (Riggar et al., 1984b).

The Bureau of Labor Statistics originally used the term "turnover" in 1966 to describe both organizational turnover accessions and separations (Price, 1977), however there are many different causes of turnover. Turnover can refer to a person who has voluntarily "quit" or "resigned", or it can be used to refer to an individual who has involuntarily "retired", "died", been "laid off", or "dismissed" (Price, 1977, p. 9). Another facet of turnover is the idea that there is controllable versus uncontrollable turnover. Controllable turnover does not include things such as death or retirement (van der Merwe \& Miller, 1975). Turnover for purposes of studying the potential correlation to organizational stress, strain and coping refers to "individuals who voluntarily leave organizations" (Price, 1977, p. 9). This idea of the movement of an individual in and out of organizations is a dynamic concept and the implications of voluntary turnover are of interest to researchers because it is this type of turnover that is more affected and controlled by an organization's supervisors (Price, 1975). In addition, Barrett et al. (1997) found correlations between overwork, downsizing, cost containment, little reward or recognition to stress and burnout.

Based on the analysis of turnover intentions reported by individuals, it is expected that turnover intentions will provide an accurate view of the potential turnover in the field of rehabilitation. Mobley (1977) developed a model of employee's turnover decision process that begins with the evaluation of one's current position and eventually leads to either voluntarily quitting or staying through a process of evaluation. The evaluation process examines job satisfaction or lack of, the expected costs of leaving one's current position, as well as the existing alternatives. The intention to leave occurs immediately before one actually either leaves the current position or stays (Mobley, 1977). Therefore we would hypothesize that the intention to leave one's position, or turnover intention, is a good predictor of actual turnover.

Coined by Freudenberger (1974), the term burnout is most commonly used in the human service fields to "refer to a state of emotional exhaustion caused by excessive psychological and emotional demands made on people helping people" (Jackson, Schwab, \& Schuler, 1986). Physical exhaustion, emotional exhaustion, and mental exhaustion make up three important components of burnout (Pines \& Aronson, 1988). Maslach and Schaufeli (1993) report that factors relates to one's occupation are more highly correlated to burnout than "biographical or personal factors" (p. 7). In addition, Elman and Dowd (1997) have demonstrated that: "excessive job demands, lack of proper performance recognition, unclear performance expectations, role conflict, poor attitudes toward work, emotional distress, and frequent physical 
symptoms seem to be the most salient features that correlated with burnout" (p. 64). Helping professionals such as therapists, social workers and doctors are susceptible to burnout (Minirth et al., 1986). Pines and Aronson (1988) point out that "individuals who are potentially the most valuable resources in an organization because of their idealism and concern are precisely those who are most apt to burn out" (p. 193).

Subsequently, since work stress is correlated with burnout (Cherniss, 1980) and turnover is linked to burnout (Maslach \& Florian, 1988; Noworol, Zarczynski, Fafrowicz, \& Marek, 1993; Pines \& Aronson, 1988), turnover intention is a viable variable for further analysis. In addition, if burnout is linked to both turnover and stress, it is imperative to conduct an analysis of the relationship between stress and turnover intentions to determine if a correlation exists. It is believed that turnover can negatively affect an organization's effectiveness, which refers to the degree to which an organization is able to achieve its' goals (Price, 1975). Therefore, an understanding of the types of occupational stress that rehabilitation counselors are privy to and the related reasons that they voluntarily leave an organization could assist supervisors and administrators in developing programs to address occupational stress and at the same time increase their organization's effectiveness.

Barrett et al. (1997) found a one percent increase in the rate of turnover in the field of rehabilitation counseling. This rate of turnover, while not statistically significant still indicates that employee turnover in the field of rehabilitation has either remained relatively the same or has even increased, somewhat over the past ten years (Barrett et al., 1997). The combination of an Individual Data Form which specifically addresses turnover intentions and the OSI-R provides an objective measurement of any correlation between these two variables, as well as any other existing relationships between the variables being studied.

\section{Historical Perspective}

The foundations were laid for the current concept of stress, strain, and coping as far back as ancient Greece with the work of Hippocrates, otherwise referred to as the "father of medicine" (Selye, 1993, p. 8). Modern day stress theorists credit Cannon and Selye for their innovative and groundbreaking work that has formed the basis from which the predominant and most widely researched theories stem. Selye (1974) defined stress as "the nonspecific response of the body to any demand" (p. 27). It is through his research as an endocrinologist that he found that various biological responses could be predicted based the introduction of a toxin into a specific bodily system (Selye, 1974). It was these findings that prompted Selye to develop his theory of the general adaptation syndrome (GAS), which he described as three distinct stages:

1. Alarm reaction - an organism is exposed to a stimulus that it has not adapted to. It reacts by going into a phase dominated by a shock response that eventually leads to another response in which the organism begins to counteract the initial alarm reaction.

2. Stage of resistance - the organism has adapted to the stressor or stimulus and any symptoms improve or disappear.

3. Stage of exhaustion - if the stressor has been particularly severe and prolonged the symptoms reappear and the organism becomes exhausted and/or death might occur. (Selye, 1983, p. 4)

Another important contribution that Selye made was the distinction between the effects of different types of stress. Specifically he thought that there was eustress, which was harmless or seemingly beneficial stress, and distress, which was harmful or bad stress (Selye, 1976). Selye's framework for stress is conceptually similar to the idea that stress, an alarm reaction, if not 
modified by coping, or some resistance to that stress, leads to strain, or the equivalent to exhaustion in Selye's GAS model (Trivette, 1993).

Theoretical Approaches to the Relationships Between Stress, Strain, and Coping

There are a wide variety of various definitions and theories pertaining to the dynamic construct of stress. In an attempt to organize all of these theories Ghadially and Kumar (1987) suggested that there were at least three distinct orientations, which were: (a) stimulus-based, (b) response-based, and (c) interactional. Subsequent literature supports the idea that there are three different theoretical approaches to the concept of stress (Richard \& Krieshok, 1989; Ryan, 1996; Trivette, 1993).

\section{Stimulus-based}

Kahn (1986) defines stimulus-based stress as "external forces or conditions that are hypothesized or demonstrated to have negative (painful, damaging, incapacitating) effects on the organisms of interest" (p. 42). Stimulus-based stress theorists believe that the factors in the environment exert an influence on an individual (Derogatis \& Coons, 1993; Lazarus \& Folkman, 1986b; Meichenbaum, 1986). Essentially this model proposes that external stressors in the environment result in a stress reaction or strain (Cox, 1978). In addition, different categories of stimulus stressors have been identified in terms of their ability to induce stress such as: (a) acute, time-limited stressors; (b) chronic intermittent stressors; (c) stressor sequences; and (d) chronic stressors (Derogatis \& Coons, 1993).

\section{Response-based}

"Stress is seen as a psychological or physiological reaction to a stressor or stressors" (Richard \& Krieshok, 1989). This was also the viewpoint that Selye and others utilized as the foundation for their work as stress researchers (Chesney \& Rosenman, 1983; Selye, 1974, 1976, 1983, 1993). Although in one of his later publications Selye admitted, "I should have called my phenomenon the 'strain reaction' and that which causes it 'stress,' which would parallel the use of these terms in physics" (Selye, 1976, p. 50). If this had been the case, than current theorists might have considered Selye's model interactional or transactional versus response-based.

\section{Interactional}

The interactional approach to stress incorporates both stimulus-based and response-based approaches (Cox, 1978; Richard \& Krieshok, 1989). This theory has also been referred to as the stimulus-response interaction (Greenberg, 1999) and is sometimes used to refer to the transactional approach (Derogatis \& Coons, 1993). The interactional approach stipulates that situational variables interact with personal variables from which strain results (Ryan, 1996).

Current research supports the theoretical construct set forth by the interactional approach. Fogerty et al. (1999) conducted four separate studies which analyzed occupational stress, strain, and coping through path analysis. It was concluded in all four studies that stress and coping variables were able to significantly predict the amount of variance in strain (Fogerty et al., 1999), thus substantiating the interactional model from which the OSI-R stems. Decker and Borgen (1993) also advocate for an interactional approach for researchers interested in studying variables related to occupational stress, strain, and coping because they feel it "fully examines the individual's unique psychological experience of work" (p. 477).

Cox and McKay took the interactional approach to stress one step farther and have proposed that there is another facet to this approach (Cox, 1978). This theory has been referred to as transactional (Greenberg, 1999). The transactional approach incorporates the stimulus, response, cognitive appraisal of the stressor, coping style of the individual, psychological 
defenses, and social milieu into account (Folkman \& Lazarus, 1988a, 1988b). A transactional approach suggests that, "not only does the individual mediate the impact of environmental stimulus upon responses, but, in addition, the perceptual, cognitive, and physiological characteristics of the individual affect and become a significant component of the environment" (Derogatis \& Coons, 1993).

\section{Coping}

There are many different approaches to the concept of coping. Osipow (1998) proposed an interactive orientation that assumes that coping plays an integral role in the effect that stress has upon strain. In and of itself, "coping consists of cognitive and behavioral efforts to manage specific external and/or internal demands that are appraised as taxing or exceeding the resources of the individual" (Folkman \& Lazarus, 1988b). Ryan (1996) described four primarily strategies that individuals employ to respond to job stress: "changing one's psychological condition, physical condition, behavior and/or work environment" (p. 23). Folkman and Lazarus (1988a) found that emotions in stressful events were mediated by coping however they also reported problems with the retrospective self-reporting procedure they used to collect this data.

Cherniss (1980) believes that "coping with stress depletes psychological energy... the more stress the helper experiences from any source, the less energy is available for empathy and caring" (p. 19). Kampfe et al. (1995) found that undergraduates in rehabilitation education programs used problem-focused and seeking-social-support strategies during their internships. Osipow (1998) categorized coping behaviors into recreational activities, self-care behaviors, social support systems, and rational/cognitive skills (operationalized definitions are provided in the section regarding occupational coping factors).

\section{Strain}

Strain, for purposes of this research, was viewed interactively as the result of stressors that cause stress, which is then mediated by coping. Thus strain can also be considered the reaction to stress. Physical and psychological strain can "range from a barely perceptible increase in pulse rate to disabling physical and emotional illness" (McLean, 1979, p. 35). Osipow and Spokane (1987) identified four types of strain. They divided strain into the following categories: vocational, psychological, interpersonal, and physical. These four categories of strain remained the same for the OSI-R as they were in the original OSI (Osipow, 1998).

Coping as a Mediating Variable for Strain: Perception and Appraisal

Osipow and Spokane (1987) developed their instrument based on a model where coping behaviors mediate the stress-strain relationship and that "given equal amounts of stress, strain will be moderated by coping" (Richard \& Krieshok, 1989, p. 118). It is this model that has formed the theoretical basis of the OSI and OSI-R. Based on the premise that coping mediates the relationship between stress and strain, we would expect stress and strain to be positively correlated, however coping and strain to be negatively correlated. Decker \& Borgen (1993) reported that although there is a commonly found relationship between stress, strain, and coping; research supporting the interacting effects "between stress and coping and their impact on strain" is not consistently supported (p. 471). However, results supporting the assumption are amble and include, but are not limited to, studies that utilized path analysis (Fogarty et al., 1999), hierarchical regression (Decker \& Borgen, 1993), and multivariate analysis of covariance (Richard \& Krieshok, 1989). 
Some theorists have examined personality and the possible correlation to coping (Farruggia, 1986; Lazarus, 1986b). Farruggia (1986) disregarded personality traits as "likely sources of predictive information" (p. 4). Similarly, Lazarus (1986a) believed that personality predispositions, not currently being examined in this research study, effect the cognitive appraisal of a stressful event. Based on this premise Turnipseed (1999) mentions the effect that an individual's appraisal can have, which "renders the potentially stressful events less overwhelming and undesirable" (p. 1199). Conceptually, what is considered or appraised as stressful by one individual may not be considered stressful by another (Meichenbaum, 1986). The stress reaction depends on the appraisal of the significance by the individual (Lazarus, 1986a). Therefore it could be concluded that appraisal acts as a type of coping mechanism by which strain, the outcome of excessive stress, is reduced.

It might also be reasonable to suspect that coping applied by different people will affect the individual's exposure to the stress in the first place. Using the OSI, Sandu and Das (1998) found that "employees who rate the work culture to be soft were less efficient in applying the coping strategies than the employees who rate their work culture to be synergetic" (p. 17). This supports the possibility that the perception of a situation impacts the type of stress experienced and subsequent coping mechanisms utilized to reduce strain.

\section{Occupational Stress: Relevant Theoretical Issues}

Occupational stress has been widely studied, which is not surprising considering that occupational stress potentially "costs organizations millions of dollars each year through lost productivity, absenteeism, accidents, and insurance payouts" (Sutherland, Fogarty, \& Pithers, 1995 , p. 293). The following section is a review of two theories, role theory and personenvironment fit, that are frequently mentioned in the occupational stress literature and have the most relevancy to this research study.

\section{Role Theory}

In order to fulfill expected service outcomes "over the last decade human service agencies in most western economies have undergone major organizational restructuring and redefinitions of professional roles" (Biggs et al., 1995). One of the basic premises the role theory is that various occupational roles that individuals engage in may be stressful regardless of their actual occupation, suggesting that stress found in various work roles may be stressful for all workers. Osipow and Spokane (1987) described six work roles that they felt were stressful regardless of an individual's actual vocational choice. These six roles were also utilized in the revised version of the OSI and include: (a) role ambiguity, (b) role insufficiency, (c) role overload, (d) role boundary, (e) responsibility, and (e) physical environment (Osipow \& Spokane, 1987; Osipow, 1998).

\section{Person-Environment Fit}

A review of the literature suggests that researchers have attempted to find an explanation regarding the potential relationships that exist between stress, an individual, and the environment. It has been theorized that if there is not an accurate fit between the person and the environment, strain will occur (French, Caplan, \& Harrison, 1982). More specifically, a personenvironment (P-E) fit suggests that individuals fit certain occupations based on the interaction of a multitude of variables. Theoretically, P-E fit "predicts that the magnitude of strain experienced by an individual is proportional to the degree of misfit between the individual and their occupation" (Pithers \& Soden, 1999, p. 58). Individuals "vary in their needs and abilities just as jobs vary in their incentives and demands" (French et al., 1982). Lazarus and Folkman (1986b) 
believe that the interaction between how an individual affects the environment and vice versa is a complex bi-directional process that is a result of a variety of factors and not any single variable.

The P-E fit theory has attracted researchers who believe there is some efficacy in its' relationship to stress (Pithers \& Soden, 1999; Sutherland et al., 1995). This theory was lent some empirical evidence by Sutherland et al. (1995). Their research supported the idea that stress and strain is "inversely related to measures of P-E fit" (Sutherland et al., 1995, p. 306). Both the OSI (Osipow \& Spokane, 1987) and the OSI-R (Osipow, 1998) mention the need for further validation studies to examine P-E fit and the relationship to stress and strain.

Rehabilitation Counselors and Occupational Stress

Elman and Dowd (1997) suggest that for therapists there is a "heavy demand to give emotionally on the job" (p. 57). Vocational placement coordinators, operating in roles similar to that of rehabilitation counselors, indicated four main types of stressors: (a) time pressure/workload (e.g. too many clients, not enough time generally); (b) societal attitudes (e.g. employers view of clients as 'cheap labor'); (c) problems with clients (e.g. clients difficult to contact, clients not truthful and/or motivated); and (d) personal motivation/adjustment problems (e.g. difficult to be positive when it seems unrealistic to do so) (Flett \& Biggs, 1992). The results of another research study were indicative of the fact that "the interaction of the individual and the counseling environment seems to play an important role in determining the level of counselor stress" (Sowa, May, \& Niles, 1994, p. 27).

Interestingly, another variable that has been mentioned in the literature, but is not being studied in this study, is the difference between administrators (non-direct care providers) and their staff (direct care providers) in terms of burnout in the field of rehabilitation (Marini, Todd, \& Slate, 1995; Riggar, Godley, \& Hafer, 1984b). In one study it was reported that there was no difference between the direct care providers versus non-direct care providers in occupational stress, strain, or coping (Marini et al., 1995). However, Riggar et al. (1984b) found that rehabilitation administrators have higher scores on job satisfaction than direct care providers.

\section{Occupational Stress Inventory Revised Edition (OSI-R)}

The OSI has been viewed as a viable instrument to measure occupational stress, strain, and coping as evidenced by an eclectic range of studies ranging from the issue of lesbian identity and disclosure in the workplace (Driscoll, Kelley, \& Fassinger, 1996) and the hardy personality at work in the health care industry (Turnipseed, 1999) to predicting occupational strain and job satisfaction (Fogarty et al., 1999). Osipow (1998) indicated the main reasons the OSI was developed and a subsequent revision made were:

a. to develop generic measures of occupational stressors that would apply across different occupational levels and environments; and

b. to provide measures for an integrated theoretical model linking sources of stress in the work environment, the psychological strains experienced by individuals as a result of work stressors, and the coping resources available to combat the effects of stressors and to alleviate strain. (p. 1)

Other than revisions to the normative data, the addition of several new items, and the modification of others no major changes have been indicated in the OSI-R manual (Osipow, 1998), demonstrating that the integrity of the original model has not been significantly altered in the revised version of the instrument. As with the OSI (Osipow \& Spokane, 1987), the OSI-R model illustrates an interactive approach to the concept of stress, strain, and coping with each having a separate section of test items. 
The OSI-R's three dimensions are defined as the Occupational Roles Questionnaire (ORQ), Personal Strain Questionnaire (PSQ), and the Personal Resources Questionnaire (PRQ). Each dimension has its' own scales which assess specific characteristics that subsequently contribute to the total overall score. The three dimensions can be used together, like in this study, or individually based on the research questions. The ORQ includes ten questions regarding each of the following: (a) role overload, (b) role insufficiency, (c) role ambiguity, (d) role boundary, (e) responsibility, and (f) physical environment. The PSQ includes ten questions regarding each of the following: (a) vocational strain, (b) psychological strain, (c) interpersonal strain, and (d) physical strain. The PRQ includes ten questions about each of the following: (a) recreation, (b) self-care, (c) social support, and (d) rational/cognitive coping.

\section{Research Support}

There are at least twenty-four published studies that have used the OSI in the stress related literature, however very few that use the OSI-R that was only recently published in 1998. Osipow (1998) refers in the OSI-R manual to a study conducted by Elam (1997) that was used to examine the correlation between the OSI and OSI-R. The results indicated that the correlation between items was sufficient enough to generalize validity results from one to the other (Osipow, 1998). Therefore in the following section, references to the scales of the OSI-R predominantly utilize data based on the old version of the OSI or similar constructs used by other researchers.

Occupational Stress, Strain, and Coping

In this section, the three main dimensions of the OSI-R and their corresponding scales are examined. When available, relevant research related directly to each dimension and scale is examined. Specifically, research regarding rehabilitation counseling and related fields will be referenced when available, however if not available, other research related to occupational stress, strain and coping resources will be cited. For purposes of clarification, when referring to the OSI or OSI-R scales, capital letters will be used. Lower case letters will represent similar constructs that are used by other researchers in the literature.

\section{Occupational Stress Factors}

Occupational stress factors are measured in the dimension of the OSI-R referred to as the Occupational Roles Questionnaire (ORQ). The ORQ consists of six scales: Role Overload (RO), Role Insufficiency (RI), Role Ambiguity (RA), Role Boundary (RB), Responsibility (R), and Physical Environment (PE). These scales are designed to measure occupational stress (Osipow, 1998) through defined work roles that were identified and subsequently associated with stress in the literature (McLean, 1974).

Role Overload. Role Overload (RO) "measures the extent to which job demands exceed resources (personal and workplace) and the extent to which the individual is able to accomplish workloads" (Osipow, 1998, p. 2). Role overload can result in an employee "experiencing anger and frustration toward persons believed responsible for the overload in work" (Marini et al., 1995, p. 123). Decker and Borgen (1993) found that Role Overload for counselors was modestly correlated with strain but not correlated with job satisfaction.

Trivette (1993) found that Role Overload scores for elementary school counselors were in the average range for both genders. However, Trivette (1993) found that counselors who worked at two or more schools had higher stress levels. In addition, working at two or more school settings was significantly correlated with higher Role Overload scores in comparison to counselors working at only one school. Aitken and Schloss (1994) found that for institutional 
staff working with individuals with intellectual disabilities, Role Overload was reported to be high due to the physical environment.

Ryan (1996) found that Role Overload scores for Licensed Professional Counselors (LPC) were in the average range for both genders. However, LPCs who met with 2.25 clients per day had higher Role Overload scores than those who met with more clients per day (Ryan, 1996). In addition, Ryan (1996) found that LPCs who did not have any self-referred clients had higher Role Overload scores than those with one to two thirds self-referred clients.

Role Insufficiency. Role Insufficiency (RI) "measures the extent to which the individual's training, education, skills, and experience are appropriate to job requirements" (Osipow, 1998, p. 2). This variable has produced mixed results with regard to counselors. Clemons (1988) reported that Role Insufficiency explained "the greatest amount of variance in general job satisfaction" (p. 148). Trivette (1993) found that Role Insufficiency scores for elementary school counselors were in the average range for both genders. Ryan (1996) also found that Role Insufficiency scores for Licensed Professional Counselors (LPC) were in the average range for both genders. However, LPCs who had caseloads consisting of one to twothirds legally mandated clients had higher Role Insufficiency scores than those who have less than one-third mandated clients (Ryan, 1996).

Role Ambiguity. Role Ambiguity (RA) "measures the extent to which priorities, expectations, and evaluation criteria are clear to the individual" (Osipow, 1998, p. 2). Turnipseed (1999) found that control, a "tendency to feel and act as if one can exert influence" (p. 1201) in the workplace, was negatively correlated to role ambiguity. This suggests that if an individual "believes that he can influence the circumstances, the ambiguity may not be experienced" (Turnipseed, 1999, p. 1212). Decker and Borgen (1993) also found that "having ambiguous or unchallenging work was more predictive of adverse outcomes of strain and job dissatisfaction" (p. 476).

This is an important variable to study since "role ambiguity has been found to be correlated with job dissatisfaction, job threat, and anxiety" (Marini et al., 1995, p. 123). Jayaratne \& Chess (1984) found that social workers working in child welfare and community mental health agencies reported higher levels of role ambiguity than social workers in family services. Trivette (1993) found that Role Ambiguity scores for elementary school counselors were in the average range for both genders. However, Trivette (1993) found Role Ambiguity was significantly higher for counselors who worked at three or more schools.

Aitken and Schloss (1994) found that for institutional staff working with individuals with intellectual disabilities, Role Ambiguity was reported to be high due to the physical environment. Ryan (1996) found that Role Ambiguity scores for Licensed Professional Counselors (LPC) were in the average range but males scored higher than females. In addition, Role Ambiguity was the highest for LPCs who met with clients three days per week (Ryan, 1996). Ryan (1996) also found that LPCs who did not have any self-referred clients had higher Role Ambiguity scores than those with up to one-third self-referred clients.

Role Boundary. Role Boundary (RB) "measures the extent to which the individual is experiencing conflicting role demands and loyalties in the work setting" (Osipow, 1998, p. 2). It has been suggested in the literature that Role boundary is synonymous with role conflict (Aitken \& Schloss, 1994; Ryan, 1996; Trivette, 1993), which has been found to be a strong predictor of burnout (Aitken \& Schloss, 1994).

Jayaratne \& Chess (1984) found that social workers involved in child welfare scored significantly higher scores on role boundary measures than social workers in family services or 
community mental health agencies. Aitken and Schloss (1994) found that for institutional staff working with individuals with intellectual disabilities, Role Boundary was reported to be high due to the physical environment.

Trivette (1993) found that Role Boundary scores for elementary school counselors were in the average range for both genders. However, Trivette (1993) found that Role Boundary was significantly higher for counselors who worked at three or more schools.

Ryan (1996) also found that Role Boundary scores for Licensed Professional Counselors (LPC) were in the average range for both genders. However, LPCs working 1 to 3 sessions per day had higher Role Boundary scores than LPCs who had 7 to 9 sessions per day (Ryan, 1996). In addition, Ryan (1996) found that LPCs who did not have any self-referred clients had higher Role Boundary scores than those with up to one to two-thirds self-referred clients. Role Boundary scores were also higher for LPCs who did not have any mandated clients (Ryan, 1996).

Responsibility. Responsibility (R) "measures the extent to which the individual has, or feels, a great deal of responsibility for the performance and welfare of others on the job" (Osipow, 1998, p. 2). Decker and Borgen (1993) found that Responsibility for counselors was modestly correlated with strain but not correlated with job satisfaction.

Trivette (1993) found that Responsibility scores for elementary school counselors were in the average range for both genders.

Ryan (1996) found that Responsibility scores for Licensed Professional Counselors (LPC) were in the average range but males scored higher than females. In addition, Responsibility was the highest for LPCs who met with clients three days per week (Ryan, 1996). Ryan (1996) also found that LPCs who had 4 to 6 sessions per day had higher Responsibility scores than LPCs who had 7 to 9 sessions per day.

Physical Environment. Physical Environment (PE) "measures the extent to which the individual is exposed to high levels of environmental toxins or extreme physical conditions" (Osipow, 1998, p. 2). Trivette (1993) found that Physical Environment scores for elementary school counselors were in the average range for both genders. The same was reported for LPCs (Ryan, 1996).

Aitken and Schloss (1994) found that for institutional staff working with individuals with intellectual disabilities, Role Overload, Role Ambiguity, and conflicting role demands was reported to be high due to the physical environment. Pithers and Soden (1999) found that among vocational teachers, men scored significantly higher than women on this variable and "quite likely because of their exposure to more extreme workplace conditions" (p. 57).

\section{Occupational Strain Factors}

Based on the theoretical foundation on which the OSI-R was designed, strain is believed to be the result of the interaction of individually experienced stress and subsequent coping. The Personal Strain Questionnaire (PSQ) was developed to measure psychological strain that is reflected in "affective, subjective responses of various types" (Osipow, 1998, p. 1). The PSQ consists of four scales: Vocational Strain (VS), Psychological Strain (PSY), Interpersonal Strain (IS), and Physical Strain (PHS).

Vocational Strain. Vocational Strain (VS) "measures the extent to which the individual is having problems in work quality or output" and their "attitudes toward work" (Osipow, 1998, p. 2). Trivette (1993) found that Vocational Strain scores for elementary school counselors were in the average range for both genders. Similar results were reported for LPCs (Ryan, 1996). However, LPCs working in public agencies reported higher Vocational Strain scores than LPCs 
in private practice (Ryan, 1996). Turnipseed (1999) found that Vocational Strain had a negative relationship with control, when hardiness composite scores were regressed post hoc, thus "an individual who is able to exert influence is less likely to experience problems with quality or quantity of output" (p. 1212).

Psychological Strain. Psychological Strain (PSY) "measures the extent of psychological and/or emotional problems being experienced by the individual" (Osipow, 1998, p. 2). It has been found that vocational teachers who reported more congruence between their personality and their job, based on Holland's personality types, scored significantly lower on Psychological Strain than individuals who reported less congruence between their personality and occupation (Pithers \& Soden, 1999).

Trivette (1993) found that Psychological Strain scores for elementary school counselors were in the average range for both genders. However, Trivette (1993) found that counselors with one child had higher scores for Psychological Strain than counselors with two children. Ryan (1996) found that Psychological Strain scores for LPCs were in the average range, however LPCs who received stress related treatment had higher scores. Ryan (1996) also found that LPCs working as professors in a program preparing counselors displayed lower Psychological Strain scores than those who worked in a mental health agency and counselors in private practice scored lower than those in agency settings.

Interpersonal Strain. Interpersonal Strain (IS) "measures the extent of disruption (e.g. withdrawal or aggressiveness) in interpersonal relationships" (Osipow, 1998, p. 2). Clemons (1988) reported that 81 out of 244 counselors responded to the statement "stress at work impacts on stress in the rest of your life" (p. 124). Thus indicating that interpersonal strain may result from occupational stress. Trivette (1993) found that Interpersonal Strain scores for elementary school counselors were in the average range for both genders. However, Trivette (1993) found that counselors with one child had higher scores for Interpersonal Strain than counselors with two children. Ryan (1996) found that Interpersonal Strain scores for LPCs were in the average range for both males and females. However, LPCs who received stress related treatment as well as counselors aged 28 to 37 reported higher scores.

Physical Strain. Physical Strain (PHS) "measures complaints about physical illness and/or poor self-care habits" (Osipow, 1998, p. 2). Pithers and Soden (1999) found that among vocational teachers, women scored significantly higher than men when reporting amounts of Physical Strain. Trivette (1993) found that Physical Strain scores for elementary school counselors were in the average range for both genders. However, Trivette (1993) found that counselors with one child had higher scores for Physical Strain than counselors with two children. Ryan (1996) reported that scores for Physical Strain were in the average range, however LPCs who received stress related treatment had higher scores. Ryan (1996) also found that LPCs working as professors in a program preparing counselors displayed lower Physical Strain scores than those who worked in a mental health agency and counselors in private practice scored lower than those in agency settings.

\section{Occupational Coping Factors}

Newman and Beehr (1979) provided the foundation for the third dimension of the OSI-R referred to as the Personal Resources Questionnaire (PRQ). The PRQ measures coping resources (Osipow, 1998) and consists of four scales: Recreation (RE), Self-care (SC), Social support (SS), and Rational/cognitive coping (RC).

Recreation. Recreation (RE) "measures the extent to which the individual makes use of and derives pleasure and relaxation from regular recreational activities" (Osipow, 1998, p. 2). 
Cunningham (1989) reported, "productive and satisfying use of recreation and leisure time has been identified as a potential coping strategy in reducing stress" (p. 652). Trivette (1993) found that Recreation scores for elementary school counselors were in the average range for both genders. However, Trivette (1993) found that counselors with children had lower scores for Recreation than counselors with no children. In addition, counselors aged 56 and up scored higher on Recreation scores than counselors aged 40 to 47.9 .

Using the OSI and a demographic questionnaire, it was determined that counselors who had participated in stress management courses reported significantly higher levels of Recreation than counselors who did not (Sowa et al., 1994). Ryan (1996) reported that LPCs scored in the average range for Recreation scores. However LPCs who received stress related treatment scored lower on Recreation than those who have not received treatment. In addition, LPCs who reported meeting with clients 1 to 2 days per week had higher scores than those who met with clients five to six days a week (Ryan, 1996).

Self-care. Self-care (SC) "measures the extent to which the individual regularly engages in personal activities which reduce or alleviate chronic stress" (Osipow, 1998, p. 2). Farber and Heifetz (1982) have advocated:

that therapists need activities and interests outside the sphere of psychotherapy in order to renew themselves-to escape, at least temporarily, the stresses of therapeutic work and to prevent the therapeutic mode from totally dominating their perspective. (p. 299)

Using the OSI and a demographic questionnaire, it was determined that counselors who had participated in stress management courses reported significantly higher levels of Self-care than counselors who did not (Sowa et al., 1994).

Trivette (1993) found that Self-care scores for elementary school counselors were in the average range for both genders. However, Trivette (1993) found that counselors with children had lower scores for Self-care than counselors with no children. In addition, counselors aged 56 and up scored higher on Self-care scores than counselors' ages 32 to 39.9 and 40 to 47.9 (Trivette, 1993). Ryan (1996) reported that LPCs scored in the average range for Self-care scores. However, LPCs who reported meeting with clients one to two days per week had higher scores than those who met with clients five to six days a week (Ryan, 1996).

Social Support. Social Support (SS) "measures the extent to which the individual feels support and help from those around him/her" (Osipow, 1998, p. 2). Hemmelgarn and Laing (1991) found that women with more social support experienced less role strain than women with less social support, thus supporting the hypothesis that social support acts as buffer. It was found that over $50 \%$ of therapists reported relying on support from other therapists and that "most therapists found the role of support systems essential" (Farber \& Heifetz, 1982, p. 298).

Trivette (1993) found that Social Support scores for elementary school counselors were in the average range for both genders. Similarly Ryan (1996) found the same results for LPCs. However, LPCs employed as counselors in elementary through high school settings reported lower scores than LPCs employed as professors (Ryan, 1996). In a study of female social workers, researchers found a positive relationship between social support and job satisfaction as well as a negative relationship between social support and burnout (Melamed, Kushnir, \& Meir, 1991). However, the researchers examined control and social support without reporting which had a more significant impact on job satisfaction and burnout.

Elman and Dowd (1997) found that burnout and Social Support was negatively correlated, suggesting that Social Support functions as an adaptive coping behavior. Pithers and 
Fogarty (1995) reported that males scored on average lower than females in regards to Social Support. Pithers and Soden (1999) also found that vocational teachers that were females, scored higher than males on this variable. They also found that vocational teachers who reported more congruence based on Holland's personality types also scored significantly higher on Social Support than individuals who reported less congruence between their personality and occupation (Pithers \& Soden, 1999). In conclusion, the researchers suggest, "social support may be promoted by any activities (such as team building) which facilitate interpersonal relationships and communication" (Melamed, Kushnir, \& Meir, 1991, p. 51)

Rational/Cognitive Coping. Rational/Cognitive Coping (RC) "measures the extent to which the individual possesses and uses cognitive skills in the face of work-related stresses" (Osipow, 1998, p. 2). Folkman and Larazus (1988b) found that individuals who "engage in rational, planful problem-solving ... are less likely to communicate hostility than those who use confrontive coping" (p. 313). Sowa et al. (1994) reported that counselors who reported high occupational stress did not report lower levels of Rational/Cognitive Coping resources. This indicates that counselors who have been taught rational/cognitive problem solving skills may not necessarily translate into these counselors having "coping skills to deal with stressful environments" (Sowa et al., 1994, p. 27).

Trivette (1993) found that Rational/Cognitive coping scores for elementary school counselors were in the average range for both genders. Ryan (1996) had similar findings for LPCs. However, LPCs who received stress related treatment scored lower on Rational/Cognitive coping than those who have not received treatment. In addition, LPCs who reported meeting with clients 1 to 2 days per week had higher scores than those who met with clients 5 to 6 days a week (Ryan, 1996).

Correlates of Occupational Stress, Strain, and Coping

A review of the literature suggests that results regarding specific demographic variables are inconsistent (Ryan, 1996; Trivette, 1993). In the following section various demographic variables considered important for further evaluation are discussed as they pertain to the current research study. These variables include: (a) age, (b) gender, (c) ethnicity, (d) certification status, (e) experience, (f) number of clients on caseload, and (h) number of hours worked per week.

Age

Research examining age as a variable in the interaction of stress, strain, and coping have had inconsistent findings. Coping mechanisms were found to be utilized less by younger workers than by older workers, with the exception of Social Support which appears to remain relatively stable throughout the life-span (Osipow, Doty, \& Spokane, 1985). Older workers also expressed decreased amounts of environmental stress but increased amounts of Role Overload and Responsibility than younger workers (Osipow et al., 1985).

Biggs et al. (1995) found that age for rehabilitation counselors was significantly positively correlated with job satisfaction. However, age was not shown to be a factor that was correlated with occupational stress, strain and coping in a sample consisting of 153 participants (Fogerty et al., 1999), 83 participants (Richard \& Krieshok, 1989), and 113 participants (Hemmelgarn \& Laing, 1991). Decker and Borgen (1993) also found that age was not substantially contributing to the variance of strain when using hierarchical regression analysis.

Age was not found to be a significant variable for elementary school counselors on stress and strain measures, however results indicated that older counselors had higher coping scores than younger ones (Trivette, 1993). This indicates "at least some coping strategies/resources are better utilized by older counselors as compared to some younger counselors" (Trivette, 1993, p. 
115). Ryan (1996) reported that LPCs aged 28-37 scored significantly higher than counselors aged 47-79 on Interpersonal and Psychological Strain. Overall, age as a significant variable has mixed results and is of interest in this study.

\section{$\underline{\text { Gender }}$}

There is continuous debate regarding the role that gender plays in relation to occupational stress. Results from studies have been inconsistent and thus the issue of gender continues to be of interest. Gender has not consistently been shown to be a significant variable and research has shown few differences between males and females (Decker \& Borgen, 1993; Elman \& Dowd, 1997; Osipow \& Davis, 1988; Osipow et al., 1985; Trivette, 1993). Fogerty et al. (1999) also did not find gender to be significantly correlated with stress, strain, or coping.

A study by Marini et al. (1995) found that males scored significantly higher than females on Physical Environment, Role Boundary, and Role Insufficiency while women only scored higher on Role Overload. These results indicate that males may experience occupational stress differently than females. Niles and Anderson (1993) found that males and females scores on the OSI differed substantially indicating that gender has an impact on how stress is experienced. They reported that "female clients reported average scores for occupational stress, strain, and coping, men reported higher stress and strain scores and lower coping scores" (Niles \& Anderson, 1993, p. 83).

Richard \& Krieshok (1989) also found gender differences, however they found that women in higher occupational ranks experience more strain than men when they controlled for age, stress, and coping. Ryan (1996) found that male LPCs had significantly higher stress scores than females, with males scoring higher on Role Ambiguity and Responsibility. Studies examining various types of counselors had mixed results, making gender a variable of interest.

Ethnicity

Ethnicity is an important variable to study because "some studies have documented cultural differences in stress" (Ghadially \& Kumar, 1987, p. 2). However, Indian, Taiwanese, and American women reported similar strains (Ghadially \& Kumar, 1987, p. 2) suggesting that culture differences between these groups may not be a factor for this variable. Pithers and Soden (1998) reported, "overall it was found that stress and strain similarities between two national groups far outweighed the differences" (p. 269). Overall, most studies lack enough subjects for results to be generalized (Biggs et al., 1995; Ghadially \& Kumar, 1987; Marini et al., 1995; Osipow et al., 1985; Ryan, 1996). Therefore, ethnicity is a variable of interest due to the large sample size proposed for this research study and the possibility of having a larger pool of individuals from various ethnicities from which data can be analyzed.

\section{Certification Status as a Rehabilitation Counselor}

In order to receive certification as a certified rehabilitation counselor (CRC) individuals must prove a "level of education, experience, and knowledge competencies required to provide counseling services to individuals with disabilities" (Gandy \& Martin, 1999, p. 111). An individual certified as a CRC has demonstrated to the Commission on Rehabilitation Counselor Certification (CRCC) a "minimum level of competency in rehabilitation counseling" (Havranek $\&$ Brodwin, 1994). Havranek and Brodwin (1994) stress the importance of receiving certification by stating:

With respect to hiring requirements, public accreditation agencies (e.g. CARF and $\mathrm{JCAH}$ ) and private companies (insurance rehabilitation) generally designate the CRC, Certified Insurance Rehabilitation Specialist (CIRS), or Certified Case 
Manager (CCM) as a minimum standard for the provision of professional

services. (p. 372)

Riggar, Garner, \& Hafer (1984a) believe that for rehabilitation counselors, "it is clearly possible to prevent, reduce or cure burnout through training activities" (p. 97). Biggs et al. (1995) found that rehabilitation counselors with no tertiary education reported more psychological distress then counselors with tertiary education. This indicates that more education correlates with a significant reduction in stress.

Sowa et al. (1994) also found that $82 \%$ of counselors in their study reported that training helped them deal with stress. However, after running MANOVA's they determined that there was no significant difference between the "occupational stress, personal strain, and coping resources of counselors who perceive their counselor education training as helpful in coping with occupational stress was no more or less than that of those counselors who do not perceive their counselor training as helpful" (Sowa et al., 1994, p. 26).

Due to the inconsistent results of previous studies, this research hypothesizes that additional education or training might serve as an effective coping resource. Therefore if additional training, including higher educational attainment, acts as a coping resource than we would expect that CRCs would experience less job strain than counselors that are not certified.

\section{Experience: Number of Years in the Profession}

Following with the aforementioned arguments regarding the expected decreased amount of stress for individuals who are certified, we would expect that the longer that someone is in the field of rehabilitation, the more training they would have received, either through on-site or inservice trainings. Thus, the longer an individual is in the field or more experience they have, the less stress they will experience. Biggs et al. (1995) found that the more years a rehabilitation counselors had been employed (length of service) was positively correlated with job satisfaction. In addition, we would expect that the longer an individual is in the field, the higher up in the ranks the individual the individual will be, therefore not experiencing the same amount of stress of direct-care providers (Marini et al., 1995; Riggar et al., 1984a).

\section{Practice Setting}

Roles and functions of a rehabilitation counselor will be closely tied to and depend upon the type of setting in which he or she practices (Wright \& Emener, 1991). Rehabilitation counselors work in a wide variety of settings: (a) public-non-profit agencies, (b) private-nonprofit agencies, and (c) private-for-profit agencies (Gandy \& Martin, 1999). Public agencies that are non-profit would include state and federal vocational rehabilitation programs. Examples of private non-profit organizations range from sheltered workshops, vocational training centers, or residential facilities. In addition, rehabilitation counselors are now working in "mental health, substance abuse treatment, geriatric rehabilitation, medical/allied health case management, employee assistance programs, disability management, and private practice/consultation" (Koch $\&$ Rumrill, 1997, p. 9). Private practice would include individuals who are self-employed, manage their own companies, or work in areas such as workers' compensation, long-term disability, or forensic rehabilitation (Havranek \& Brodwin, 1994).

Aitken and Schloss (1994) found that staff working in community based residential placements with individuals with intellectual disabilities, had lower levels of stress and burnout than staff working in large institutions. A study examining occupational settings for psychologists found that individuals in private practice reported less job related stress, health concerns, and mental health problems than psychologists working in academic settings (Boice \& Myers, 1987). Farruggia (1986) compared rehabilitation counselors in the public and private 
sectors and found that no significant differences in overall job satisfaction existed between the two groups. However, other studies have found differences in levels or stress, strain and coping between public and private sector counselors (Boice \& Myers, 1987; Ryan, 1996).

\section{Average Number of Clients on Caseload}

Emotional exhaustion, along with depersonalization and decreased personal accomplishment, are considered to be the three main dimensions of burnout (Pines \& Aronson, 1988). "Emotional exhaustion refers to a depletion of one's emotional resources and the feeling that one has nothing left to give to others at a psychological level" (Maslach \& Florian, 1988, p. 85). Differences in perceptions about caseloads may be a limiting factor in accurately studying this variable. One study found varying qualitative differences in how social workers reported their caseloads in relation to their perceived and actual work load (Jayaratne \& Chess, 1984). However, Maslach and Florian (1988) found that "rehabilitation counselors with large caseloads experienced greater emotional exhaustion" (p. 91). Therefore it could be deducted that higher caseloads might be associated with higher burnout rates and possibly increased turnover rates.

\section{Average Number of Hours Worked Per Week}

In a study that used a combination of the PSQ and the Gray's Measure of Role Strain, "women who were employed full-time had significantly higher role strain than those who worked part-time or in not-regularly scheduled positions" (Hemmelgarn \& Laing, 1991, p. 12). One of the inclusion criteria for this research study is rehabilitation counselors who currently work full-time primarily in the field of rehabilitation, therefore the variable of interest is number of hours worked beyond the typical forty hours a week. It is hypothesized that counselors that work more than forty hours a week will experience more stress than counselors working only forty hours, which could potentially lead to increased turnover rates.

\section{Summary}

This chapter has looked at historical perspectives as well as theories that have formed the foundation for research regarding stress, strain, coping, and turnover intentions. The OSI-R and its scales were defined with relevant research discussed. Demographic variables have also been examined with an emphasis on the importance of an analysis of the defined variables. 


\section{CHAPTER III}

\section{METHODOLOGY}

Studies of turnover are important because of the loss of valuable resources, both time and personnel, that impact the field significantly. Researchers have looked at many factors related to turnover intentions. This study in particular looks at how stress, strain, and coping directly and indirectly affect the turnover intentions of rehabilitation counselors.

\section{Research Questions}

This study is primarily interested in how stress, strain, and coping directly and indirectly affect the turnover intentions of rehabilitation counselors. The main hypothesis is that stress has direct effects on turnover intentions but also indirect effects through strain and coping resources. This study also looks at the relationships between stress, strain, and how they are affected by coping resources as well as how all three effect turnover intentions. Of secondary interest are the relationships between stress, strain, coping resources, turnover intentions, and various demographic variables.

$\underline{\text { Research Questions }}$

1. What are the effects of stress, strain, and coping on the turnover intentions of rehabilitation counselors? More specific questions are:

a. What is the direct effect of stress on turnover intentions?

b. What is the indirect effect of stress mediated by coping and strain on turnover intentions?

c. What is the direct effect of stress on coping?

d. What is the direct effect of stress on strain?

e. What is the indirect effect of coping mediated by strain on turnover intentions?

f. What is the direct effect of strain on turnover intentions?

In addition, differences in occupational stress, strain, and coping factors for rehabilitation counselors are examined based on the following demographic variables: (a) age, (b) gender, (c) ethnicity, (d) certification status as a rehabilitation counselor, (e) number of years in the profession, (f) practice setting, (g) average number of clients per caseload, and (h) hours worked per week.

\section{Sample/Population}

The population consists of rehabilitation counselors that belong to the American Rehabilitation Counselors Association (ARCA), a division of the American Counselors Association (ACA). The ARCA reports that it's members are predominantly: rehabilitation counselors who help people with physical, mental, or social disabilities maximize their potential. These counselors work with clients who have disabilities in order to help them resolve personal and vocational problems. They also use the counseling process to facilitate the client's adjustment to his or her disability.(http://www.nchrtm.okstate.edu/arca/member.html)

The American Counselors Association (ACA) supplied a list of a randomly selected sample from the population described above. The sample consisted of approximately 1,000 individuals chosen from the total population of ARCA members. Only rehabilitation counselors identifying themselves as primarily employed as rehabilitation counselors full-time were included in the final analyses. 


\section{Instrumentation}

The instrumentation used was the Occupational Stress Inventory Revised Edition (OSI-R) and an Individual Data Form. Data from these instruments provided the basis for all subsequent analysis used to answer the defined research questions.

\section{Individual Data Form}

An Individual Data Form (Appendix A) was utilized to gather information regarding demographic variables directly related to this study: (a) age, (b) gender, (c) ethnicity, (d) certification status as a rehabilitation counselor, (e) number of years in the profession, (f) practice setting, (g) average number of clients per caseload, and (h) hours worked per week. Six additional questions were added to the Individual Data Form. Two of the questions were utilized to assess perceived overall job stress and whether treatment had been sought for stress related problems. Finally, four additional questions were used to address the issue of turnover intentions.

\section{The Occupational Stress Inventory Revised Edition}

The Occupational Stress Inventory Revised Edition (OSI-R) (Appendix B) was developed by Osipow in 1998 and is not intended for clinical utilization but rather for research purposes. The OSI-R was based upon a previous version of the instrument that was developed by Osipow and Spokane in 1987 to measure occupational adjustment on three different dimensions. The OSI-R's three dimensions are defined as the Occupational Roles Questionnaire (ORQ), Personal Strain Questionnaire (PSQ), and the Personal Resources Questionnaire (PRQ). Each dimension has its' own scales which assess specific characteristics that subsequently contribute to the total overall score. The three dimensions can be used together, like in this study, or individually based on the research questions. The three dimensions are further divided into the following scales:

1. Occupational Roles Questionnaire (ORQ) - Role Overload, Role Insufficiency, Role Ambiguity, Role Boundary, Responsibility, and Physical Environment.

2. Personal Strain Questionnaire (PSQ) - Vocational Strain, Psychological Strain, Interpersonal Strain, and Physical Strain.

3. Personal Resources Questionnaire (PRQ) - Recreation, Self-care, Social Support, and Rational/Cognitive Coping.

Each scale is comprised of ten items, with the total number of items for all scales being 140. The ORQ consists of sixty items and the PSQ and PRQ have forty items each. Reading the instructions and responding to the test items takes approximately thirty minutes to complete and requires approximately a fifth grade reading level. Osipow (1998) articulates that care should be used if the OSI-R is administered to individuals to whom English may be a secondary language. Additional cautions are made regarding the valid administration of the OSI-R, for example:

The OSI-R assumes that the respondent is physically and emotionally capable of meeting the normal demands of testing with self-report instruments. Individuals whose cognitive abilities may be compromised by the effects of recent drug use, withdrawal from drugs or alcohol, exposure to toxic chemicals, or disorientation resulting from neurological disorder or disease should be tested with caution. Administrators should also be alert to physical or sensorimotor deficits, such as lack of visual acuity or visual field deficits, that could affect an individual's ability to complete the OSI-R in a valid manner. Individuals who are experiencing 
an acute illness or chronic condition may not be capable of providing valid responses, and testing should be deferred until a later date. (Osipow, 1998, p. 5)

All participant responses are based on a five point Likert scale and include five anchor points: rarely or never, occasionally, usually, often, and most of the time. Responses are hand scored and a separate recording sheet is used to record the data. T-score conversion tables for the conversion of scale raw scores based on the normative sample are included in the manual (Osipow, 1998).

Norms. Norms are provided separately based on gender and were established using a sample of 983 adults who were all currently employed in various occupations. Occupations of participants included: (a) administrative/executive $(\mathrm{N}=6)$; (b) scientist/professional $(\mathrm{N}=14)$; (c) business manager $(\mathrm{N}=3)$; (d) supervisor $(\mathrm{N}=9)$; (e) office worker $(\mathrm{N}=17)$; (f) technical specialist $(\mathrm{N}=9)$; $(\mathrm{g})$ sales representative $(\mathrm{N}=1)$; (h) retail worker $(\mathrm{N}=1)$; (i) skilled worker/tradesperson $(\mathrm{N}=5)$; $(\mathrm{j})$ assembly line worker $(\mathrm{N}=4) ;(\mathrm{k})$ laborer/maintenance worker $(\mathrm{N}=5)$; (l) firefighter $(\mathrm{N}=12)$; $(\mathrm{m})$ public safety/police $(\mathrm{N}=5)$; and $(\mathrm{n})$ military $(\mathrm{N}=9)$. Occupations were also categorized into groups for purposes of norming. These groups are based on occupational groups defined in 1996 by the Bureau of Labor Statistics (Osipow, 1998). Occupational groups are defined as follows: (a) executive, (b) professional, (c) technical, (d) marketing, (e) administrative support, (f) public service/safety, and (g) agriculture/production/laborer.

The sample is more heavily loaded based on higher educational achievement, however Osipow (1998) reports "considerable effort was made to obtain an adequate sample of high school graduates and individuals with less than a $12^{\text {th }}$-grade education" (Osipow, 1998, p. 7). The mean age was reported to be 36.3 years with $63 \%$ of participants being male and a total of $85 \%$ being Caucasian.

Reliability. Reliability estimates were determined by test-retest and internal consistency analyses. The OSI-R was administered to 62 Air Force Cadets (Lombard, 1997), with test-retest correlations ranging from .39 to .74. Osipow (1998) reports that "only two correlations were less than .50 , and all correlations between the two administrations were significant at the .01 level" (p. 24).

Using the normative sample, the alpha coefficients of reliability ranged from .88 to .93. The alpha coefficient for each dimension is .88 for ORQ, .93 for PSQ, and .89 for PRQ. The fourteen scales have alpha coefficients ranging from .70 to .89 and are reported in the OSI-R manual (Osipow, 1998) to be comparable to the original OSI reliability estimates (Osipow \& Spokane, 1987).

Validity. Validity data for the OSI and OSI-R is reported in the OSI-R manual to be based on: (a) convergent validity studies; (b) factor analyses; (c) correlational studies of the relationships of the scales to variables of practical and theoretical importance; (d) studies using the scales as outcome measures following stress reduction treatment; and (e) studies of the stress, strain, and coping model employing comparisons of selected criterion groups. However, in order to make a comparison between the OSI and the OSI-R, a study utilizing 45 highway patrol cadets was conducted so that the necessary correlations could be analyzed (Elam, 1997). The results suggested that the correlations were similar enough to indicate that the OSI-R could use the validity generalized from the original OSI.

Osipow (1998) reported that Guetter (1997), in an unpublished study, examined concurrent validity using the OSI-R with two other inventories and found that the measures were all correlated in "predictable ways" (p. 27). In terms of correlational studies, Fogarty et al. 
(1999) using the OSI found that for stress, strain and coping "correlations among the different variables were all significant $(\mathrm{p}<.05)$ and in line with expectations" (p. 436). Specifically, they found in their first study that stress directly affected strain positively $(b=.48)$, coping affected strain negatively $(b=-.14)$, stress negatively affected coping $(b=-.12)$, and the whole model predicted 55\% of variance in strain (Fogarty et al., 1999). In addition, Osipow (1998) reported, "treatment studies reveal that the PSQ and PRQ are sensitive outcome measures of treatment effects" with a "lack of change in stress scores (ORQ), as opposed to strain scores (PSQ)" (p. 35). This is expected based on the predicted hypothesis that coping mediates the relationship between stress and strain.

\section{Data Collection Process}

The data collection process was conducted by a mail distribution of the following; preletter, survey packet, postcard reminder, and a follow-up survey packet (Appendix C). In addition, phone call follow-ups were made to randomly selected individuals who did not respond to the previous mailings (Appendix A). This mail survey procedure was initially designed by Dillman (1978), endorsed by de Vaus (1996), and subsequently used on two similar research studies with positive results (Ryan, 1996; Trivette, 1993). All returned surveys were coded to track response dates and to note any usual pattern of responses. The following procedure was used:

\section{Pre-letter}

Three days before the initial mailing of the survey packet an introductory letter was mailed to all potential participants. The letter briefly explained the purpose of the study, the importance of this type of research, the degree of confidentiality, and offered general encouragement to participate in the research endeavor.

\section{Initial Mailing}

The first mailing contained a cover letter reiterating the information in the pre-letter as well as the survey materials. Survey packets consisted of the OSI-R and the Information Data Form. A self-addressed and stamped envelope was included to facilitate the ease of return to the researcher.

\section{Postcard Reminder}

One week after the initial mailing of the survey packet, a reminder postcard was sent to all participants. The postcard served to remind participants to return survey materials if they have not already, as well as offer appreciation to those whose materials have been returned. The postcard also indicated to individuals who have not received a packet where to reach the researcher collect or via email so that a packet can be disbursed to them again.

\section{Follow-up Mailing}

Two weeks after the initial mailing another complete survey packet was sent to those participants who had not yet responded. Included in this survey packet was a letter from the chairpersons of the dissertation committee encouraging participation. Once again a selfaddressed and stamped envelope was included to facilitate the ease of return to the researcher.

\section{Phone Follow-up}

Four weeks after the follow-up mailing, which is six weeks after the initial mailing, a random sample consisting of $10 \%$ of non-responders was contacted. The phone interview was used to gather the following information: (a) age, (b) gender, (c) ethnicity, (d) years worked as a rehabilitation counselor, (e) certification status as a rehabilitation counselor, (f) full or part time status, (g) estimated job stress, (h) estimated non-job stress, (i) intention to remain in field of 
rehabilitation counseling, and (j) why they choose not to participate in the study. The purpose of the phone follow-up was to assess whether or not there was any unusual pattern of non-response.

\section{Data Analysis}

\section{Data Management}

Data was analyzed utilizing the SPSS 9.0 (1998) for windows statistical program. Handling outliers and missing data was determined upon further analysis and was deemed to be appropriate to the procedures outlined.

\section{Procedures}

Data was analyzed utilizing the following procedures:

1. Descriptive statistics was calculated for demographic variables. This provided a profile of the population and answered research questions related to rehabilitation counselors' levels of stress, strain, and coping.

2. Validity and reliability was analyzed to determine the appropriateness of the OSI-R for use with the rehabilitation counselor population. Scores for the ORQ, PSQ, and PRQ was correlated in order to examine independence among the three dimensions and in order to compare them to scores provided in the manual. Correlations were also run on each of the scale scores and were subsequently compared to see that the expected hypothesized relationships appeared. Correlations were also run between the ORQ, PSQ, and the PRQ, and the Individual Data Form questions designed to access global job, non-job stress, and intent to remain in the field. This allowed for a comparison between what the OSI-R measures and the participant's perceived stress as well as factors related to turnover intentions such as intention to stay using Cronbach's alpha.

3. The relationship between stress, strain, and coping with regards to demographic variables was analyzed by comparing each demographic variable to the overall ORQ, PSQ, and PRQ scores. Demographic variable categories were developed after an analysis of the descriptive statistics. T-tests were used to analyze dichotomous variables, while Analysis of Variance (ANOVA) was used to analyze variables with three or more levels. Any other considerations, logistic or otherwise, are noted in the results section.

4. Path analysis, which is a regression-based method, was conducted to determine the direct and indirect effects of stress, strain, coping, on turnover intentions. Hypothesized relationships (Figure 1.0) include:

1) Coping will mediate the relationship between stress and strain.

2) Stress will be positively correlated with strain and turnover intentions.

3) Stress will be negatively correlated with coping.

4) Coping will be negatively correlated with strain and turnover intentions.

5) Strain will be positively correlated with turnover intentions. 


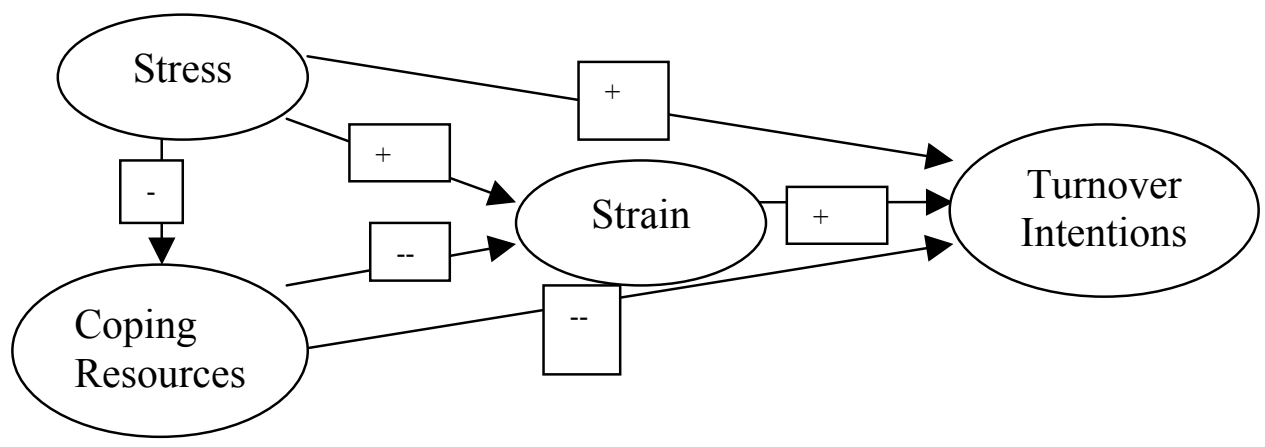

Figure 1.0. Path analysis of the hypothesized relationship between stress, strain, coping and turnover intentions.

\section{Summary}

This chapter served to review the methodology that was utilized for this study. The research questions were restated and the norms, reliability, and validity of the Occupational Stress Inventory Revised Version (OSI-R), were reviewed. Finally, the proposed sample, data collection procedure, instrumentation, data management, and procedures were stated. 


\section{CHAPTER IV}

\section{RESULTS}

The purpose of this research study was to determine the extent of influence that various identified stress, strain, and coping factors have on turnover intentions of rehabilitation counselors. Descriptive statistics are reported on the turnover intentions of participants who considered themselves practicing rehabilitation counselors. Descriptive statistics and frequencies are also presented for each variable. The means, standard deviations, and correlations for all of the variables can be found in Appendix D. Reliabilities for each scale and subscale are also reported in Appendix D and are compared to the reliability estimates stated in the manual for the Occupational Stress Inventory Revised Edition (Osipow, 1998).

In addition, results pertaining to the effects of exogenous and endogenous variables on turnover intentions are presented. The effect of each of the variables upon turnover intention is reported and interpreted. The hypothesized model is presented in Figure 2.0 while Figure 3.0 represents the tested model with its corresponding path coefficients. Finally, the direct, indirect, and total effects are reported in Table 2.0.

While interpreting the tested model it should be noted that paths that are .05 or greater are considered substantively significant (Pedhazur, 1982). While information regarding each variable will be reported, when reporting the regression analysis, only paths that are statistically significant $(\mathrm{p}<.05)$ are included. The model presented in Figure 3.0 shows only statistically significant paths with all of the non-significant paths removed.

\section{Total Sample Profile}

The American Rehabilitation Counselor Association (ARCA) reports that their association's membership is comprised primarily of practicing rehabilitation counselors (http://www.nchrtm.okstate.edu/arca/member.html). Since this was the target population, a mailing list that consisted of the members of the Association was provided by the American Counseling Association (ACA). The entire association of active members was sampled ( $\mathrm{N}=$ 982), excluding international members. The total number of responses was $67 \%(\mathrm{~N}=657)$. However, 24 participants indicated that they felt that they were not eligible to participate because they were not rehabilitation counselors and did not offer any other information, 3 individuals sent back notes refusing to participate, 16 mailings were returned as undeliverable by the Postal Service, 14 individuals sent notes indicating that they were not eligible to participate because they were on the complimentary ARCA mailing list or members because of the position they held at their job. Therefore, the preliminary data set consisted of 600 individuals. Only 195 of these 600 individuals answered "yes" to the question: "Are you currently employed as a rehabilitation counselor?" These findings indicate that the ARCA is not primarily comprised of practicing rehabilitation counselors, thus leaving the data set for purposes of this study at $\mathrm{N}=$ 195.

Finally, a random sample consisting of $10 \%(\mathrm{~N}=32)$ of the individuals who did not respond to the survey was contacted. There was not an evident pattern found in the reasons given by these individuals for not responding. However, the most frequently stated reason was that the individuals believed that they were not eligible to participate because they did not consider themselves to be employed as a practicing rehabilitation counselor.

Descriptive Statistics and Correlations for Demographic Variables

The Individual Data Form was utilized to collect information regarding the sample. The number of participants who considered themselves to be rehabilitation counselors was $\mathrm{N}=195$. 
However, 2 individuals returned only the Occupational Stress Inventory Revised Edition (OSI-R) and not the Individual Data Form, 8 individuals returned the Individual Data Form and not the OSI-R, 19 individuals did not fill out the back of the Individual Data Form, 19 individuals indicated that they were only employed part-time, 1 individual only worked on a contractual basis, and 1 individual volunteered as a rehabilitation counselor. Therefore, the total number of participants with complete data and who indicated that they were employed full-time as a rehabilitation counselor was $\mathrm{N}=145$. Of these 145 individuals, $66 \%$ reported that their job title was "rehabilitation counselor", while $34 \%$ reported having a different job title but indicated that they are performing in the role of a rehabilitation counselor at work. All statistics reported hereafter are based upon the data consisting of 145 participants. Due to the number of variables examined, each demographic variable will be discussed individually.

$\underline{\text { Age }}$

Participants ranged in age from 23 to 78 years $(\mathrm{N}=141)$. The mean age was 44 , with a standard deviation of 11.08. Using bivariate correlations, it was found that age is negatively correlated with both turnover intentions (-.219) and strain $(-.233)$ at the $p<.01$ level of significance (Appendix D). This indicates that as age increases, turnover intentions and strain decrease. Due to the correlation of age with turnover intentions and strain, it was added to the tested model (Figure 2.0) and will be discussed during the path analysis section of this chapter.

Gender

Participants ( $\mathrm{N}=141)$ included 52 males (37\%) and 89 females (63\%). Gender did not have a significant relationship with stress, strain, coping resources, or turnover intentions. This was also found in previous literature (Decker \& Borgen, 1993; Elman \& Dowd, 1997; Fogerty et al., 1999; Trivette, 1993) and is further supported by these findings (Appendix D).

Ethnicity

Participants $(\mathrm{N}=141)$ were predominantly Caucasian $(\mathrm{N}=124,87.9 \%)$. There were $2(1.4$ \%) Hispanic, 11 (7.8\%) African American, and 1 (.7\%) Asian respondents. There were $3(2.1 \%)$ respondents that chose "other" for ethnicity. Ethnicity was not found to have a significant relationship with stress, strain, coping resources, or turnover intentions (Appendix D). However, it should be noted that only a small number of minority participants are represented in this sample (12\%), therefore the findings may not be generalizable. This lack of generalization has been noted by other researchers (Biggs et al., 1995; Marini et al., 1995; Ryan, 1996) and further research needs to be conducted in order to draw any definitive conclusions about ethnicity.

\section{Certification Status as a Rehabilitation Counselor}

From our sample $(\mathrm{N}=141), 83$ participants $(58.9 \%)$ reported that they were certified as rehabilitation counselors and $58(41.1 \%)$ indicated that they were not certified. Of the participants that were certified $(\mathrm{N}=83), 73$ individuals recorded the number of years they had been certified. The average number of years of certification was 8.87 with a range from 4 months to 27 years and a standard deviation of $8.37(\mathrm{~N}=73)$. While over half of the participants were certified, CRC status was not found to have a significant relationship with stress, strain, coping resources, or turnover intentions (Appendix D). This specific variable was not studied in previous literature and although it was not significant in this study, it may deserve further attention due to the correlation with experience (Appendix D). 


\section{Experience}

Experience was determined by taking half of the years an individual was employed parttime and adding it to the number of years an individual was employed full-time $(1 / 2 \mathrm{pt}+\mathrm{ft}=$ number of years experience). The range of experience $(\mathrm{N}=139)$ was from 3 months to 51 years. The average number of years an individual was employed was 10 years and three months with a standard deviation of 9.9. Bivariate correlations revealed that there is a relationship between experience and strain. Experience is negatively correlated with strain $(-.202)$ at the $p<.05$ level of significance (Appendix D). This indicates that as the number of years an individual gains experience working as a rehabilitation counselor increases, the amount of strain they experience decreases. Due to the correlation of experience with strain, it was added to the tested model (Figure 2.0) and will be discussed during the path analysis section of this chapter.

\section{Practice Setting}

Based on responses to the Individual Data Form, counselors indicated the setting in which they practiced $(\mathrm{N}=141)$. The findings show that counselors were predominately employed in a public agency $(\mathrm{N}=67,47.5 \%)$. However, $28(19.9 \%)$ counselors were employed in private non-profit, $45(31.9 \%)$ were employed in private for-profit organizations, and $1(.7 \%)$ individual was in private practice. The practice setting in which a person was employed was not found to have a significant relationship with stress, strain, coping resources, or turnover intentions (Appendix D). This was also found in previous literature that explored the differences between the private and public sectors of the rehabilitation counseling field (Farruggia, 1986).

\section{Average Number of Clients on Caseload}

The number of individuals who indicated that they have a caseload consisting of rehabilitation clients was $\mathrm{N}=131$. Of these individuals $(\mathrm{N}=131)$, the range in number of clients was from 2 to 700 . The average number of clients was 88 with a standard deviation of 102.55. The number of clients on a counselor's caseload was negatively correlated with coping resources (-.198) at the $\mathrm{p}<.05$ level of significance (Appendix D). This indicates that as the number of clients on a caseload increases, coping resources reported by rehabilitation counselors decrease. Due to the correlation of the number of clients on a caseload with coping resources, it was added to the tested model (Figure 2.0) and will be discussed during the path analysis section of this chapter.

\section{Average Number of Hours Worked Per Week}

Participants $(\mathrm{N}=139)$ worked an average of 45 hours per week with a range of 25 to 70 hours and a standard deviation of 8.37. The average number of hours an individual worked per week was not found to have a significant relationship with stress, strain, coping resources, or turnover intentions (Appendix D).

\section{Global Job and Life Stress}

Using a scale of $1-10$, with 1 being the lowest and 10 being the highest, participants were asked to rate their estimated level of global job stress and non-job or life stress. The average number indicating the amount of job related stress was 6.39 with a range of 1 to 10 and standard deviation of 2.03 (Appendix D). The average number indicating the amount of life related stress was 5.69, with a range of 1 to 10 and standard deviation of 2.32 (Appendix D). In comparison to Licensed Professional Counselors (LPCs), rehabilitation counselors had a higher average job stress score (6.39 versus 5.39) and higher average life stress score (5.69 versus 4.64) (Ryan, 1996). 
As expected, job stress and overall non-job or life stress are correlated to stress, strain, coping, and turnover intentions for rehabilitation counselors. The amount of job stress is positively correlated to stress (.482), strain (.359), and turnover intentions (.454) but negatively correlated to coping resources $(-.351)$ at $\mathrm{p}<.01$ (Appendix D). The amount of life stress is also positively correlated with stress (.203), strain (.334), and turnover intentions (.225) but negatively correlated with coping resources (-.370) at $\mathrm{p}<.01$ (Appendix D). In addition, job stress and life stress are highly correlated (.378) at the $\mathrm{p}<.01$ level (Appendix D).

\section{$\underline{\text { Stress Related Treatment }}$}

Interestingly, 47 participants (31\%) indicated that they have received treatment for stress related problems. Of those 47 people, 22 have received psychological treatment, 5 received physical treatment, 20 received both types of treatment. However, receiving treatment was not significantly correlated with stress, strain, coping resources, or turnover intentions (Appendix D).

\section{Scale Reliabilities and Correlations}

The reliability statistics for the scales and subscales of the OSI-R closely resemble those reported in the OSI-R (Osipow, 1998) manual (Appendix D). Turnover intention was measured by four items and the reliability estimate had an alpha of .9170. This indicates that the turnover scale used in this study was a highly reliable instrument in measuring the turnover intentions of rehabilitation counselor and was a viable outcome measure for this study.

To determine the relationship between stress, strain, coping resources, and turnover intentions, scale correlations were analyzed (Appendix D). Findings derived from running bivariate correlations indicate that all of the relationships between stress, strain, coping resources, and turnover intentions are statistically significant at $\mathrm{p}<.05$ (Table 1.0). Turnover intentions are negatively correlated with coping resources and positively correlated with stress and strain. Therefore as individuals' coping resources decrease, they are more likely to leave their job. In addition, as individual levels of stress or strain increase, they are more likely to leave their job as a rehabilitation counselor. Stress is positively correlated with strain and negatively correlated with coping. These results indicate that as stress increases, strain will increase and coping will decrease. Coping is also negatively correlated with strain therefore, when coping resources are limited, strain increases. These findings were also reported by Ryan (1996) and Trivette (1993) in similar studies. 
Table 1.0

Correlation Matrix for Turnover, Stress, Strain, and Coping

\begin{tabular}{|c|c|c|c|c|}
\hline & $\begin{array}{l}\text { Turnover } \\
\text { Intentions }\end{array}$ & Stress & Strain & Coping \\
\hline $\begin{array}{l}\text { Turnover } \\
\text { Intentions }\end{array}$ & 1.0 & & & \\
\hline Stress & $.546 * *$ & 1.0 & & \\
\hline Strain & $.519 * *$ & $.617 * *$ & 1.0 & \\
\hline Coping & $-.363 * *$ & $-.357 * *$ & $-.550 * *$ & 1.0 \\
\hline
\end{tabular}

** Correlation is significant at $\mathrm{p}<0.01$ 
Path Analysis

Path analysis models are "useful in graphically displaying a hypothesized pattern of causal relationships among variables" (Wells, 1993). The OSI-R (Osipow, 1998) is based on the model that hypothesizes that stress leads to strain and subsequently, stress and strain are mediated by coping (see Figure 1.0, Chapter 3). In this study, turnover intention was the primary outcome variable in the model. The purpose of the study was to assess how much variance in turnover intention can be accounted for by stress, strain, and coping.

The model (Figure 2.0) included some significant demographic variables. T-tests, bivariate correlations, and one way analyses of variances (ANOVAs) revealed that the only demographic variables with statistically significant relationships to stress, strain, coping, and turnover intentions were: age, experience measured in number of years, and the number of clients on a counselor's caseload. These variables were added to the model in an attempt to explain variance in turnover intentions based on age, experience, number of clients on a counselor's caseload, stress, strain, and coping resources.

The hypothesized model is a fully recursive model, while the final model is based on a re-estimation of the original model using a series of regression analyses. In the final model, turnover intention was regressed on strain, coping resources, stress, number of clients on a caseload, and age. Experience was dropped due to the lack of significance and while the number of clients on a caseload was not significant, when it was dropped other variables became significant thus leading to spurious results. Strain was regressed on stress, coping, and age. Coping was regressed on stress and the number of clients on a counselor's caseload. Finally, stress was regressed on age, experience and number of clients on caseload however none of these demographic variables lead to significant findings. The final model presented in Figure 3.0 shows only statistically significant paths with all of the non-significant paths removed. 


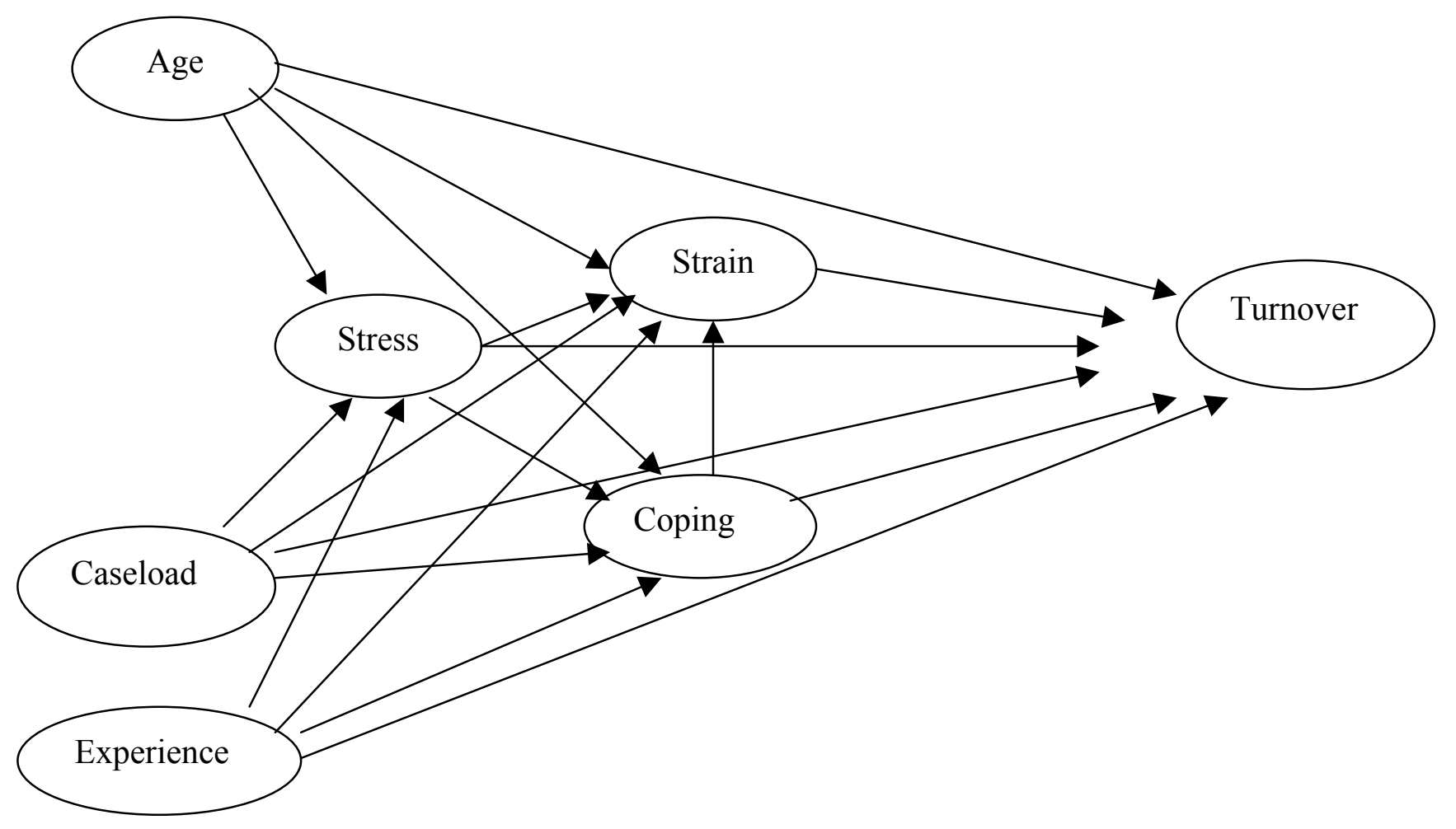

Figure 2.0. Hypothesized Model of Turnover Intentions 
Table 2.0

Direct, Indirect, and Total Effects of Age, the Number of Clients on a Caseload, Stress, Strain, and Coping Resources on Turnover Intentions of Rehabilitation Counselors

\begin{tabular}{|c|c|c|c|}
\hline & & Effects & \\
\hline Variable & Direct Effect & Indirect Effect & Total Effect \\
\hline Age & -.135 & -.035 & -.17 \\
\hline $\begin{array}{c}\text { Number of Clients } \\
\text { on Caseload }\end{array}$ & -.080 & .031 & -.049 \\
\hline Stress & $.404^{*}$ & .143 & .547 \\
\hline Coping & -.111 & -.064 & -.172 \\
\hline Strain & .173 & & .173 \\
\hline
\end{tabular}

$* \mathrm{p}<.05$

$\underline{\mathrm{R} \text {-squared }=.375, \mathrm{p}<.05}$ 


\section{Effect of Strain on Turnover Intentions}

Due to its' placement in the model, strain does not have indirect effects and therefore only the direct effect on turnover intention are interpreted. For strain, the $\mathrm{B}=.173$ is not statistically significant and is therefore not considered significant in explaining turnover intentions. This does not support the hypothesized relationship that as a rehabilitation counselor's strain increases, their turnover intentions would also increase. However, it should be noted that stress and strain are highly correlated (Table 1.0). This might explain why strain does not exhibit a significant influence upon turnover intentions but stress has a high moderate to high influence on turnover intentions. Another reason for the statistical nonsignificance of the effect of strain on turnover intentions is the statistically small sample size of the study.

\section{Effect of Coping on Turnover Intentions}

Although, coping resources have both direct and indirect effects on turnover intentions, neither of these effects are statistically significant at the $p<.05$ level. However, coping does have a significant direct effect on strain $(\mathrm{B}=-.368)$. This supports the hypothesized expectation, that as coping resources decrease an individual is more likely to experience more strain. Again, the statistically small sample size may account for the lack of support for the hypothesized relationship between the effect of coping resources on turnover intentions.

\section{Effect of Stress on Turnover Intentions}

Stress has both indirect and direct effects on the turnover intentions of rehabilitation counselors (see Figure 3.0 and Table 2.0), however the indirect effects were not considered statistically significant. The direct effect $(\mathrm{B}=.404)$ is the only statistically significant effect and is considered to have a larger and meaningful influence when interpreting the model. The amount of stress that a rehabilitation counselor reports has a significant positive effect on their turnover intentions. Therefore as stress increases, the likelihood that an individual will leave their job increases.

In addition, the hypothesized relationship between stress, strain, and coping was supported by the significant direct effect of stress on coping $(\mathrm{B}=-.346)$ and on strain $(\mathrm{B}=.484)$. In addition, the larger effect size that occurs between stress and strain $(B=.484)$ when coping is not a mediating variable, supports the hypothesis that coping resources impact the amount of strain an individual experiences when exposed to stress.

\section{Effect of Age on Turnover Intentions}

Age did not have any significant direct effects or indirect effects on turnover intentions. However, age has a significant direct effect on strain $(B=-.204)$. Thereby indicating that as a person's age increases, their strain will decrease.

\section{Effect of Experience on Turnover Intentions}

While experience was hypothesized to effect turnover intentions, experience did not have any significant direct or indirect effects on turnover intentions and was excluded from the final model (Figure 3.0). One possible explanation is the high correlation between age and experience (.634) which was significant at the $\mathrm{p}<.01$ level (Appendix D). This lead to collinearity and this variable ended up not being significant when used in the path analysis model.

\section{Effect of Number of Clients on Caseload on Turnover Intentions}

The number of clients on a counselor's caseload does not have a significant direct effect on turnover intentions, however the direct effect on coping resources was significant $(\mathrm{B}=-.179)$. 
This effect is considered moderate and indicates that as the number of clients on a caseload increase, the amount of coping resources an individual reports decreases.

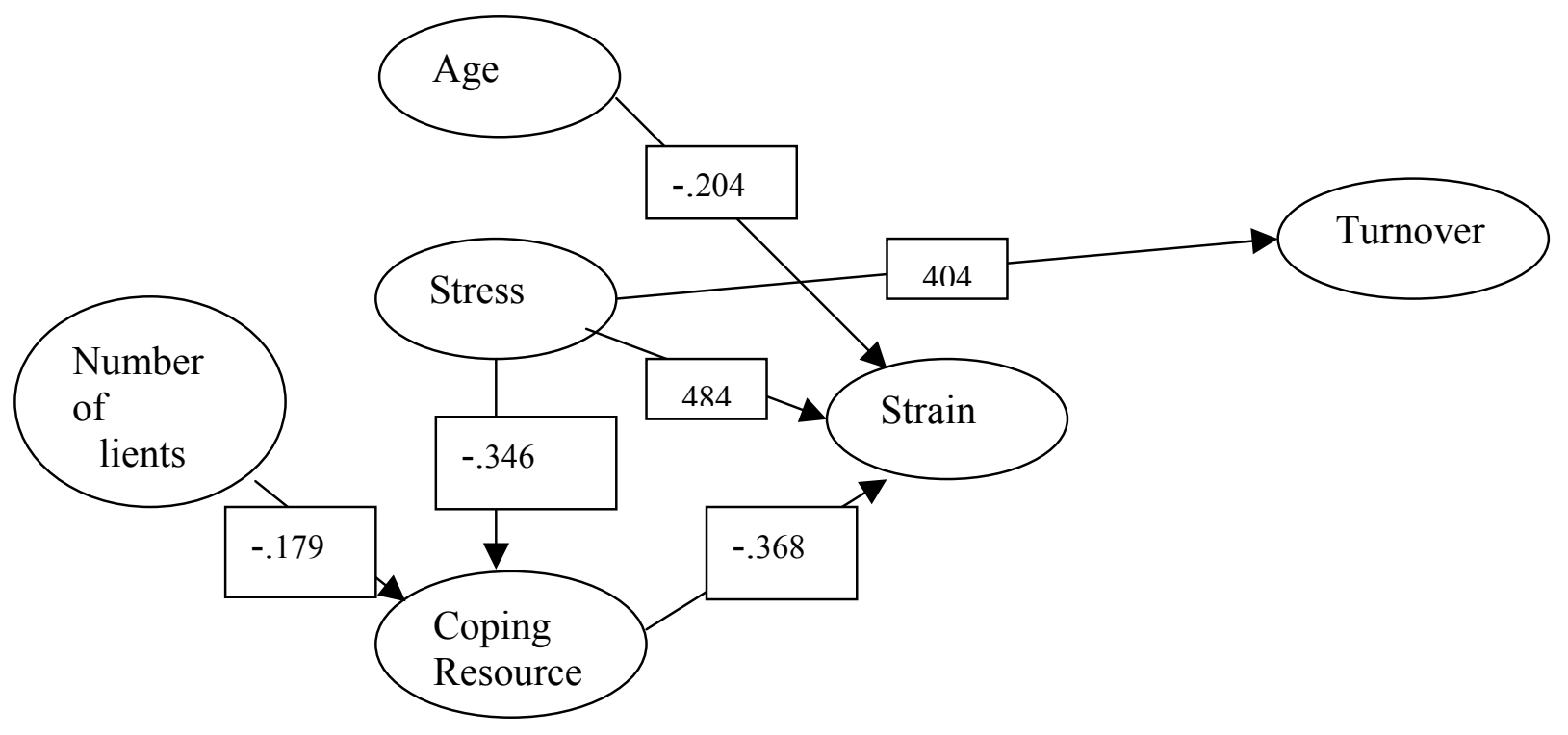

Figure 3.0. Model of Turnover Intentions

\section{Summary}

The purpose of this study was to determine the extent of influence that various identified stress, strain, and coping factors have on the turnover intentions of rehabilitation counselors. The results suggest that the factors selected, along with some of the demographic variables, are significant and have an important impact upon the turnover of counselors in the rehabilitation field. 


\section{CHAPTER V}

\section{DISCUSSION AND RECOMMENDATIONS}

In this chapter, the results of this study will be interpreted and discussed. The methodology and research results are briefly reviewed. The implications for rehabilitation professionals and rehabilitation training programs are explored. Finally, recommendations for future research are discussed.

\section{Methodology}

The purpose of this study was to examine the stress, strain, and coping resources as they related to the turnover intentions of a sample of rehabilitation counselors throughout the United States. The participants were selected to participate based on their membership in the American Rehabilitation Counseling Association (ARCA). The survey had a response rate of $67 \%$, however only a small percentage of the total responses $(\mathrm{N}=145)$ qualified for analysis based on the inclusion criteria. Participants had to consider themselves to be performing the job duties of a rehabilitation counselor full-time at the time of the survey.

Data were obtained through the use of an Individual Data Form and the Occupational Stress Inventory Revised Edition (OSI-R). The OSI has been viewed as a viable instrument to measure occupational stress, strain, and coping as evidenced by an eclectic range of studies ranging from the issue of lesbian identity and disclosure in the workplace (Driscoll, Kelley, \& Fassinger, 1996) and the hardy personality at work in the health care industry (Turnipseed, 1999) to predicting occupational strain and job satisfaction (Fogarty et al., 1999). The OSI-R's three dimensions are defined as the Occupational Roles Questionnaire (ORQ), Personal Strain Questionnaire (PSQ), and the Personal Resources Questionnaire (PRQ). Each dimension has its' own scales which assess specific characteristics that subsequently contribute to the total overall score. The three dimensions were used together in this study, however can also be used individually. The ORQ includes ten questions regarding each of the following: (a) role overload, (b) role insufficiency, (c) role ambiguity, (d) role boundary, (e) responsibility, and (f) physical environment. The PSQ includes ten questions regarding each of the following: (a) vocational strain, (b) psychological strain, (c) interpersonal strain, and (d) physical strain. The PRQ includes ten questions about each of the following: (a) recreation, (b) self-care, (c) social support, and (d) rational/cognitive coping.

Data were collected through a series of postal mailings that included: (a) a pre-letter, (b) an initial packet mailing, (c) a postcard reminder, and (d) a follow-up mailing of the packet. In addition, phone follow-ups to $10 \%$ of non-respondents was also conducted $(\mathrm{N}=33)$. Statistical procedures were done using the SSPS 9.0 (1998) statistical software. Correlations were computed for the three OSI-R domains of stress, strain, and coping resources to see if the hypothesized pattern of relationships would follow the hypothesized model. Demographic variables were selected based on theoretical considerations and past research. These variables were analyzed through bivariate correlations unless the variable was categorical with two or more levels, then T-tests or one-way analyses of variance (ANOVAs) were conducted in order to determine if significant differences existed between these levels. Stress, strain, coping, and turnover intentions were also included in the hypothesized path analysis model (Figure 2.0).

Finally, a series of regression analyses were conducted using the exogenous and endogenous variables in the model. Turnover intention was regressed on strain, coping resources, stress, number of clients on a caseload, and age. Strain was regressed on stress, coping, and age. Coping was regressed on stress and the number of clients on a counselor's 
caseload. Finally, stress was regressed on age, experience and number of clients on caseload however none of these demographic variables lead to significant effect sizes. All of the direct, indirect, and total effects were interpreted (Table 2.0) and only path coefficients that were significant were included in the final model (Figure 3.0).

\section{Results}

Information received from the Individual Data Forms was analyzed and provided the general profile of the participants $(\mathrm{N}=145)$ who responded to the survey. Respondents were on average 44 years old and $63 \%$ were female. Respondents were predominantly Caucasian $(87.9 \%)$ and worked in public rehabilitation organizations $(47.5 \%)$. Of the respondents, $(58.9 \%)$ were Certified Rehabilitation Counselors (CRC) and the average number of years they had been certified was 8.87. Respondents also reported an average 10 years and three months of experience in the field, worked an average of 45 hours per week, and had an average caseload of 88.

Path analysis was used to test a conceptual model of stress, strain, and coping resources in order to explain the turnover intention rehabilitation counselors. The results suggested that the model explains $37.5 \%(\mathrm{R}$-squared $=.375)$ of the variance in turnover intentions. The only variable with statistically significant influence on turnover intentions was stress (.402), which is considered to have a large effect. These results indicate that as an individual's stress level increases, they are more likely to leave their position as a rehabilitation counselor and seek alternative positions either within the rehabilitation field or in another industry. Therefore, the more stressed rehabilitation counselors are, the more likely they are to leave their jobs.

\section{Implications and Recommendations}

This study demonstrated the importance of the negative impact of stress. A degree of stress is inherent in the job functions associated with a career as a rehabilitation counselor. While many of the variables correlated with turnover intentions, the variable with the largest effect and that was statistically significant was stress (.402). This would suggest that while coping resources and strain are useful in examining how people deal with stress, it is the occupational stress itself that impacts the turnover intentions of rehabilitation counselors. This is an important implication because as mentioned previously, stress negatively impacts job satisfaction (Jex, 1998), performance (Jex 1998; McGuigan, 1999), productivity (Glasser, 1984; McGuigan, 1999), and job commitment (Jex, 1998).

$\underline{\text { Recommendations for Practicing Professionals }}$

Stress was measured by the Occupational Roles Questionnaire (ORQ) scale which is made of five subscales on the OSI-R. The ORQ is comprised of questions examining the effects of Role Boundary, Role Overload, Role Ambiguity, Role Insufficiency, Responsibility, and Physical Environment in creating stress. These subscales were designed to measure occupational stress (Osipow, 1998) through defined work roles that were identified and subsequently associated with stress in the literature (McLean, 1974).

Role overload "measures the extent to which job demands exceed resources" and "the extent to which an individual is able to accomplish workloads" (Osipow, 1998, p. 2). Therefore we can deduct that rehabilitation counselors are being asked to perform tasks or jobs for which they are not given the resources. This lack of perceived resources is a stressor that subsequently leads to turnover. Administrators and supervisors should be aware of and assess available resources, thereby being able to train practicing rehabilitation counselors how to utilize these resources effectively. 
Role Insufficiency "measures the extent to which the individual's training, education, skills, and experience are appropriate to job requirements" (Osipow, 1998, p. 2). Incongruence between the job requirements and feelings about an individual's role sufficiency, therefore lead to stress and the increased likelihood of job turnover. To reduce turnover intentions, rehabilitation administrators should explore an applicant's perceived abilities through training, education, skill level, and education to ensure that counselors are placed in rehabilitation roles in which they feel they have the ability to perform competently.

Role Ambiguity "measures the extent to which priorities, expectations, and evaluation criteria are clear to the individual" (Osipow, 1998, p. 2). Turnipseed (1999) found that control, a "tendency to feel and act as if one can exert influence" (p. 1201) in the workplace, was negatively correlated to role ambiguity. This suggests that if an individual "believes that he can influence the circumstances, the ambiguity may not be experienced" (Turnipseed, 1999, $p$. 1212). Decker and Borgen (1993) also found that "having ambiguous or unchallenging work was more predictive of adverse outcomes of strain and job dissatisfaction" (p. 476). Role Boundary "measures the extent to which the individual is experiencing conflicting role demands and loyalties in the work setting" (Osipow, 1998, p. 2). Rehabilitation counselors may not perceive that they have an influence on the systems in which they find themselves employed or may be experiencing conflicting demands from the various roles they play within an organization. These factors may be leading to higher turnover intentions and indicates that administrators can decrease role ambiguity by clearly stating the job expectations, priorities, and the ways in which evaluations are conducted, as well as examining the ways in which various assigned roles may be conflictual. In addition, administrators can allow and encourage rehabilitation counselors to communicate their feedback appropriately, thereby giving them a greater chance of perceiving that they are exerting influence within their assigned role and of exploring conflictual role demands.

Responsibility "measures the extent to which the individual has, or feels, a great deal of responsibility for the performance and welfare of others on the job" (Osipow, 1998, p. 2). Traditional rehabilitation counselors receive funding for their services based upon outcome measures either imposed by government programs such as Medicaid, or through private insurance. Therefore, rehabilitation counselors are highly responsible for their client's treatment outcomes, which may subsequently dictate the funding they receive for various programs or for an individual client's treatment. This high level of responsibility is a stressor and subsequently impacts turnover intentions.

Physical Environment "measures the extent to which the individual is exposed to high levels of environmental toxins or extreme physical conditions" (Osipow, 1998, p. 2). Aitken and Schloss (1994) found that working with individuals with intellectual disabilities impacted the amount of role overload, role ambiguity, and conflicting role demands due to the physical environment. So while rehabilitation counselors may not be exposed daily to environmental toxins or extreme physical conditions, working with individuals with disabilities may impact the perceived physical environmental conditions.

State rehabilitation agencies are potentially the most likely to experience higher turnover as a result of counselor stress levels, as documented in studies regarding job satisfaction (Barrett et al., 1997). State agencies could reduce turnover by offering clear evaluative criteria to counselors, as well as giving incentives or recognition for achieving state guidelines. In addition, agencies could put together in-service trainings and clear updates for the continuously changing legislative guidelines and policies that counselors find themselves inundated to keep up 
with. This will reduce the amount of role ambiguity and subsequent stress that is experienced every time a new policy is circulated or new law is passed. State agencies could also employ task forces at each locale, whose main focus is community resources and recent technological advances. These task forces could then report any changes to administrators and supervisors who can then train counselors, thus reducing role overload.

In addition, excessive amounts of responsibility could be reduced by a team approach to achieving client success. Programs such as Medicaid will only fund programs or individual clients if the evaluative criteria is being met on a continuous basis. For example, billable client contact hours for each counselor must be a specific amount in order to fund various programs. A team approach to meeting outcome criteria, for example sharing workloads as a team and evaluating who will receive what services each week offers counselors the support of a team to handle client issues and expands the knowledge about various resources. This also allows for transitions from one counselor to the next much easier and gives programs a more integrated approach to client care, as well as continues to fund the program as a whole. If one person isn't going to make their billable hours, other team members are aware of how many hours they need to do to maintain funding for that period of time. State agencies should continue to work on encouraging open communication between counselors and supervisors regarding areas of high stress and give counselors more control over their job functions in order to deter turnover.

All of these variables that are measured by the stress subscales are imposed or directly impacted by administrators within organizations, or the structure of the organizations themselves and are inherent in many of the job functions of a traditional rehabilitation counselor. This would suggest that one of the ways of reducing turnover in the field of rehabilitation counseling is to modify the job functions that rehabilitation counselors are required to perform by looking at conflicting role demands, preparation for various required job roles, physical environments, personal resources that counselors have available to them, workloads, ways in which counselors can express feedback that will be perceived as influential, and finally ways in which responsibility for individual client progress is measured.

\section{Recommendations for Rehabilitation Training Programs}

Potentially students may embark on a career in the field of rehabilitation without sufficient knowledge initially about the actual roles and job functions that practicing professionals undertake. Training programs should encourage students to explore the field of rehabilitation before beginning their studies, as well as include a course during the first semester that would present an orientation to the field. In addition, training programs should explore potential internship placements with students in order to find a variety of sites that provide a range of experiences in the field from the most typical public placements to more unusual selfemployment opportunities.

Rehabilitation counselors are also responsible for activities outside of, or in excess of, the traditional counselor activities. For example, rehabilitation counselors are responsible for being knowledgeable about a wide variety of obscure and current resources in the community that can meet the needs of individuals with rare diseases, physical conditions, or multiple psychiatric disabilities. In addition to knowing the resources, they have to understand the funding sources for these resources that match each of their client's unique and often complex physical and mental health needs. Rehabilitation counselors are also expected to have experience with or be knowledgeable about the latest technological advances that relate to assistive devices. Training programs need to be aware of the most recent innovations and incorporate experiential hands-on 
learning in order to make future counselors aware of how various devices work, as well as the pros and cons of using them to match various client needs.

Working as a rehabilitation counselor often entails having a large caseload of clients with multiple disabilities. In order to reduce stress, meet evaluation criteria successfully, and serve large numbers of clients in a timely manner, rehabilitation counselors have to be highly organized and be multitask oriented. Training programs should identify students with difficulty in these areas and evaluate with the student whether they will be able to perform the basic job functions associated with working in many organizations. This will prevent students who may not have a good match with the basic job duties from starting a job and having an unsuccessful experience, thus leaving the field entirely. Instead, professors can assist students in finding niches in the rehabilitation field in which their personality and counseling style are a good match to both the clients and the job.

\section{Recommendations for Future Research}

First, it is recommended that a larger sample of rehabilitation counselors should be obtained from an association or organization that is truly comprised of practicing rehabilitation counselors. Therefore while this was one of the largest, if not the largest, sample reflected in the literature, this sample consisted of rehabilitation counselors that belong to the American Rehabilitation Counselors Association (ARCA) and were employed full time primarily as rehabilitation counselors. Global generalization of results to individuals that work in the rehabilitation field, but do not belong to this professional association, presents a problem. Participation in a professional association, may in and of itself systematically affect the variables of interest. In addition, it would be unrealistic to conduct an environmental assessment of each participant's job site. Therefore these results should not be generalized to all rehabilitation counselors.

Second, a more multicultural representation of rehabilitation counselors should be sought in order to examine differences among stress, strain, coping, and turnover intentions between various ethnic groups of rehabilitation counselors. Ethnicity is an important variable to study because "some studies have documented cultural differences in stress" (Ghadially \& Kumar, 1987, p. 2). Like many other studies, (Biggs et al., 1995; Ghadially \& Kumar, 1987; Marini et al., 1995; Osipow et al., 1985; Ryan, 1996), the results of this one are not able to be generalized due to a small sample size.

Third, since stress was shown to have such a large influence on turnover intentions, future research might want to include more variables that measure stress. Fourth, this study was conducted on a national level and does not reflect differences between rehabilitation counselors working under a wide variety of state imposed regulations that could influence the job requirements of various geographic areas.

Fifth, researchers might want to examine more variables consistent with the job functions that rehabilitation counselors perform. Isolating variables in the rehabilitation field that are leading to high stress among counselors will enable organizations to more effectively restructure the job functions of rehabilitation counselors within their organization thus preventing turnover.

Sixth, the results showed that being a Certified Rehabilitation Counselor (CRC) did not reduce the amount of stress, strain, or turnover in the field. Being certified also did not correlate with having better coping resources. Therefore the education and experience that individuals are receiving to become a $\mathrm{CRC}$ does not correlate with the actual expectations and role functions of a practicing rehabilitation counselor. Having the additional training required for CRC certification, should act as a way to reduce stress. Certified counselors should be more aware of 
the most current resources and trends in the field, thus having more control over the services they offer. Certification should also serve to make counselors more knowledgeable about technological advances and assistive technology in such a way that they are able to serve more clients effectively thus reducing stress. One way to reduce the stress associated with working as a rehabilitation counselor is to make certification a process that encourages counselors to become more aware of ways in which they can operate within various rehabilitation organizations successfully. Certification standards should include more stringent standards for counselors to receive more on-going supervision, like the requirements for Licensed Professional Counselors (LPC) in the state of Virginia, in which a beginning or disillusioned counselor can receive support thus potentially reducing the amount of turnover in the field.

Finally, another variable explored in the literature that was not examined in this study, is the difference between administrators (non-direct care providers) and their staff (direct care providers) in terms of burnout in the field of rehabilitation (Marini, Todd, \& Slate, 1995; Riggar, Godley, \& Hafer, 1984b). In one study it was reported that there was no difference between the direct care providers versus non-direct care providers in occupational stress, strain, or coping (Marini et al., 1995). However, Riggar et al. (1984b) found that rehabilitation administrators have higher scores on job satisfaction than direct care providers. It would be important to conduct research to understand the impact of performing direct versus indirect care to clients.

\section{Conclusions}

The primary objective of this study was to test a conceptual model of stress, strain, and coping resources in order to explain the high turnover of rehabilitation counselors. The results suggest, that the model explains $37.5 \%(\mathrm{R}$-squared $=.375)$ of the variance in turnover intentions. Therefore, the variables in combination explain a large amount of the turnover intentions of rehabilitation counselors. In conclusion, the results of this study suggest that it may be the occupational roles that rehabilitation counselors have in organizations versus demographic factors or how individuals cope with occupational stress that are important when examining turnover intentions in the rehabilitation field. 


\section{REFERENCES}

Aitken, C. J., \& Schloss, J. A. (1994). Occupational stress and burnout amongst staff working with people with an intellectual disability. Behavioral Interventions, 9 (4), 225-234.

Barrett, K., Riggar, T. F., Flowers, C. R., Crimando, W., \& Bailey, T. (1997). The turnover dilemma: A disease with solutions. The Journal of Rehabilitation, 63 (2), 36-47.

Biggs, H., Flett, R., Voges, K., \& Alpass, F. (1995). Job satisfaction and distress in rehabilitation professionals: The role of organizational commitment and conflict. Journal of Applied Rehabilitation Counseling, 20 (1), 41-46.

Bloom, K. D., Buhrke, R. A., \& Scott, T. B. (1988). Burnout and job expectations of state agency rehabilitation counselors in North Dakota. Journal of Applied Rehabilitation Counseling, $\underline{19}(3), 32-36$.

Boice, R., \& Myers, P. E. (1987). Which setting is healthier and happier, academe or private practice? Professional Psychology: Research and Practice, 18 (5), 526-529.

Brenznitz, S., \& Goldberger, L. (1993). Stress research at a crossroads. In L. Goldberger $\&$ S. Breznitz (Eds.), Handbook of stress: Theoretical and clinical aspects $\left(2^{\text {nd }}\right.$ Edition) (pp. 3-6). New York: The Free Press.

Cherniss, C. (1980). Staff burnout: Job stress in the human services. Beverly Hills, CA: Sage Publications.

Chesney, M. A., \& Rosenman, R. H. (1983). In C. L. Cooper (Ed.), Stress research: Issues for the eighties (pp. 21-34). New York: John Wiley \& Sons.

Clemons, C. R., Jr. (1988). The relationship of occupational stress and certain other variables to job satisfaction of licensed professional counselors in Virginia. (Doctoral Dissertation, Virginia Polytechnic Institute and State University, 1988). Dissertations Abstracts International, 50, 360A.

Cox, T. (1978). Stress. Baltimore: University Park Press.

Cranswick, K. (1997). Burnout: A study of levels of burnout and factors responsible for burnout in rehabilitation. Journal of Rehabilitation Administration, 21 (2), 119-134.

Crimando, W., Riggar, T. F., \& Hansen, G. (1986). Personnel turnover: The plague of rehabilitation facilities. Journal of Applied Rehabilitation Counseling, 17, 17-20.

Cunningham, P. H. (1989). Stress in relation to satisfaction with leisure experienced by those performing in therapeutic recreation. Psychological Reports, 64 (2), 652.

Day, H. I., \& Chambers, J. C. (1991). Empathy and burnout in rehabilitation counsellors. Canadian Journal of Rehabilitation, 5 (1), 33-44.

de Vaus, D. A. (1996). Surveys in social research $\left(4^{\text {th }}\right.$ Edition). Guildford and Kings Lynn, England: Biddles Ltd.

Decker, P. J., \& Borgen, F. H. (1993). Dimensions of work appraisal: Stress, strain, coping, job satisfaction, and negative affectivity. Journal of Counseling Psychology, 40 (4), 470478.

Derogatis, L. R., \& Coons, H. L. (1993). Self-report measures of stress. In L. Goldberger $\&$ S. Breznitz (Eds.), Handbook of stress: Theoretical and clinical aspects $\left(2^{\text {nd }}\right.$ Edition) (pp. 200233). New York: The Free Press.

Dillman, D. A. (1978). Mail and telephone surveys. New York, NY: John Wiley \& Sons, Inc.

Driscoll, J. M., Kelley, F. A., \& Fassinger, R. E. (1996). Lesbian identity and disclosure in the workplace: Relation to occupational stress and satisfaction. Journal of Vocational Behavior, 48 (2), 229-242. 
Elam, J. (1997). [OSI and OSI-R data for equivalency study]. Unpublished raw data. In Osipow, S. H. (1998). Occupational Stress Inventory Manual (professional version). Odessa, FL: Psychological Assessment Resources.

Elman, B. D., \& Dowd, E. T. (1997). Correlates of burnout in inpatient substance abuse treatment therapists. Journal of Addictions \& Offender Counseling, 17 (2), 56-65.

Farber, B. A., \& Heifetz, L. J. (1982). The process and dimensions of burnout in psychotherapists. Professional Psychology, 13 (2), 293-301.

Farruggia, G. (1986). Job satisfaction among private and public sector rehabilitation practitioners. Journal of Rehabilitation Administration, 10 (1), 4-9.

Flett, R., \& Biggs, H. (1992). Contextual issues for vocational placement: Some preliminary findings. International Journal of Rehabilitation Research, 15 (3), 187-197.

Fogarty, G. J., Machin, A., Albion, M. J., Sutherland, L. F., Lalor, G. I., \& Revitt, S. (1999). Predicting occupational strain and job satisfaction: The role of stress, coping, personality, and affectivity variables. Journal of Vocational Behavior, 54 (3), 429-452.

Folkman, S., \& Lazarus, R. S. (1988a). Coping as a mediator of emotion. Journal of Personality and Social Psychology, 54 (3), 466-475.

Folkman, S., \& Lazarus, R. S. (1988b). The relationship between coping and emotion: Implications for theory and research. Social Science Medicine, 26 (3), 309-317.

French, R. P., Caplan, R. D., \& Harrison, R. V. (1982). The mechanisms of job stress and strain. New York, NY: John Wiley \& Sons.

Freudenberger, H. J. (1974). Staff burn-out. Journal of Social Issues, 30, 159-165.

Gandy, G. L., \& Martin, E. D. (1999). Educational and professional organizational development of the discipline of rehabilitation counseling. In G. L. Gandy, E. D. Martin, \& R. E. Hardy (Eds.), Counseling in the rehabilitation process: Community services for mental and physical disabilities $\left(2^{\text {nd }}\right.$ Edition) (pp. 104-114). Springfield, IL: Charles C. Thomas Publisher LTD.

Garske, G. G. (1996). The relationship of self-esteem to levels of job satisfaction of vocational rehabilitation professionals. Journal of Applied Rehabilitation Counseling, 27 (2), 1922 .

Garske, G. G. (1999). Rehabilitation counselor job satisfaction: Self-reported rating and recommendations. Journal of Rehabilitation Administration, 23 (1), 21-29.

Ghadially, R., \& Kumar, P. (1987). Stress, strain and coping styles of female professionals. Indian Journal of Applied Psychology, 26 (1), 1-8.

Glasser, M. A. (1984). Labor looks at work stress. In L. W. Krinsky, S. N. Kieffer, P. A. Carone, \& S. F. Yolles (Eds.), Stress and productivity (pp. 55-64). New York, NY: Human Sciences Press, Inc.

Greenberg, J. S. (1999). Comprehensive stress management ( $6^{\text {th }}$ Edition). New York: WCB/McGraw-Hill.

Havranek, J. E., \& Brodwin, M. G. (1994). Rehabilitation counselor curricula: Time for a change. Rehabilitation Education, 8 (4), 369-379.

Hemmelgarn, B., \& Laing, G. (1991). The relationship between situational factors and perceived role strain in employed mothers. Family \& Community Health, 14 (1), 8-15.

Jackson, S. E., Schwab, R. L., \& Schuler, R. S. (1986). Toward an understanding of the burnout phenomenon. Journal of Applied Psychology, 71 (4), 630-640.

Jayaratne, S., \& Chess, W. A. (1984). Job satisfaction, burnout, and turnover: A national study. Social Work, 29, 448-453. 
Jex, S. M. (1998). Stress and job performance: Theory, research, and implications for managerial practice. Thousand Oaks, CA: SAGE Publications.

Kahill, S. (1988). Symptoms of professional burnout: A review of empirical evidence. Canadian Psychology, 29, 284-297.

Kahn, R. L. (1986). On the conceptualization of stress. In A. Eichler, M. M. Silverman, $\&$ D. M. Pratt (Eds.), How to define and research stress (pp. 41-43). Washington, DC: American Psychiatric Press, Inc.

Kampfe, C. M., Mitchell, M. M., Boyless, J. A., \& Saucers, G. O. (1995). Coping strategies used by undergraduate interns: Implications for rehabilitation education. Rehabilitation Counseling Bulletin, 38 (4), 318-333.

Koch, L. C., \& Rumrill, P. D. (1997). Rehabilitation counseling outside the state agency: settings, roles, and functions for the new millennium. Journal of Applied Rehabilitation Counseling, 28 (4), 9-14.

Lazarus, R. S. (1986a). Stress: Appraisal and coping capacities. In A. Eichler, M. M. Silverman, \& D. M. Pratt (Eds.), How to define and research stress (pp. 5-12). Washington, DC: American Psychiatric Press, Inc.

Lazarus, R. S., \& Folkman, S. (1986b). Stress as a rubic. In A. Eichler, M. M. Silverman, \& D. M. Pratt (Eds.), How to define and research stress (pp. 49-53). Washington, DC: American Psychiatric Press, Inc.

Leahy, M. J., \& Szymanski, E. M. (1995). Rehabilitation counseling: Evolution and current status. Journal of Counseling and Development, 74 (2), 163-166.

Lombard, T. (1997). [OSI-R data for test-retest reliability study]. Unpublished raw data. In Osipow, S. H. (1998). Occupational Stress Inventory Manual (professional version). Odessa, FL: Psychological Assessment Resources.

McEwen, B. S., \& Mendelson, S. (1993). Effects of stress on neurochemistry and morphology of the brain: Counterregulation versus damage. In L. Goldberger \& S. Breznitz (Eds.), Handbook of stress: Theoretical and clinical aspects ( $2^{\text {nd }}$ Edition) (pp. 200-233). New York: The Free Press.

McGuigan, F. J. (1999). Encyclopedia of stress. Needham Heights, MA: Allyn \& Bacon. McLean, A. A. (1974). Occupational stress. Springfield, IL: Charles C. Thomas.

McLean, A. A. (1979). Work stress. Reading, Massachusetts: Addison-Wesley Publishing Company.

Marini, I., Todd, J., \& Slate, J. R. (1995). Occupational stress among mental health employees. Journal of Rehabilitation Administration, 19 (2), 123-130.

Maslach, C., \& Florian, V. (1988). Burnout, job setting, and self-evaluation among rehabilitation counselors. Rehabilitation Psychology, 33 (2), 85-93.

Maslach, C., \& Schaufeli, W. B. (1993). Historical and conceptual development of burnout. In W. B. Schaufeli, C. Maslach, \& T. Marek (Eds.), Professional burnout: Recent developments in theory and research (pp. 1-18). Washington, DC: Taylor \& Francis.

Meichenbaum, D. (1986). Toward a conceptualization of stress. In A. Eichler, M. M. Silverman, \& D. M. Pratt (Eds.), How to define and research stress (pp. 55-57). Washington, DC: American Psychiatric Press, Inc.

Melamed, S., Kushnir, T., \& Meir, E. I. (1991). Attenuating the impact of job demands: Additive and interactive effects of perceived control and social support. Journal of Vocational Behavior, 39, 40-53. 
Minirth, F., Hawkins, D., Meir, P., \& Flournoy, R. (1986). How to beat burnout. Chicago: Moody Press.

Mobley, W. H. (1977). Intermediate linkages in the relationship between job satisfaction and employee turnover. Journal of Applied Psychology, 62 (2), 237-240.

Newman, J. E., \& Beehr, T. A. (1979). Personal organizational strategies for handling job stress: A review of research and opinion. Personnel Psychology, 32, 1-44.

Niles, S. G., \& Anderson, W. P. (1993). Career development and adjustment: The relation between concerns and stress. Journal of Employment Counseling, 30 (2), 79-87.

Noworol, C., Zarczynski, Z., Fafrowicz, M., \& Marek, T. (1993). Impact of professional burnout on creativity and innovation. In W. B. Schaufeli, C. Maslach, \& T. Marek (Eds.), Professional burnout: Recent developments in theory and research. Washington, DC: Taylor \& Francis.

Osipow, S. H., \& Davis, A. S. (1988). The relationship of coping resources to occupational stress and strain. Journal of Vocational Behavior, 32, 1-15.

Osipow, S. H., Doty, R. E., \& Spokane, A. R. (1985). Occupational stress, strain, and coping across the life span. Journal of Vocational Behavior, 27, 98-108.

Osipow, S. H., \& Spokane, A. R. (1987). Occupational Stress Inventory Manual (research version). Odessa, FL: Psychological Assessment Resources.

Osipow, S. H. (1998). Occupational Stress Inventory Manual (professional version). Odessa, FL: Psychological Assessment Resources.

Pedhazur, E. J. (1982). Multiple regression in behavioral research. Holt, Rinehart, and Winston: Fort Worth, Texas.

Pines, A., \& Aronson, E. (1988). Career burnout. New York, NY: The Free Press.

Pithers, R. T., \& Fogarty, G. J. (1995). Occupational stress among vocational teachers. British Journal of Educational Psychology, 65, 3-14.

Pithers, R. T., \& Soden, R. (1998). Scottish and Australian teacher stress and strain: A comparative study. British Journal of Educational Psychology, 68 (2), 269-279.

Pithers, R. T., \& Soden, R. (1999). Person-environment fit and teacher stress. Educational Research, 41 (1), 51-61.

Price, J. L. (1975). A theory of turnover. In B. O. Pettman (Ed.), Labour turnover and retention (pp. 51-75). Epping, Essex: Gower Press Limited.

Price, J. L. (1977). The study of turnover. Ames, Iowa: The Iowa State University Press.

Razza, N .J. (1993). Determinants of direct-care staff turnover in group homes for individuals with mental retardation. Mental Retardation, 31, 284-291.

Richard, G. V., \& Krieshok, T. S. (1989). Occupational stress, strain, and coping in university faculty. Journal of Vocational Behavior, 34 (1), 117-132.

Riggar, T. F., Garner, W. E., \& Hafer, M. D. (1984a). Rehabilitation personnel burnout: Organizational cure. Journal of Rehabilitation Administration, 8 (3), 94-104.

Riggar, T. F., Godley, S. H., \& Hafer, M. (1984b). Burnout and job satisfaction in rehabilitation administrators and direct service providers. Rehabilitation Counseling Bulletin, 27, 151-160.

Riggar, T. F., Hansen, G., \& Crimando, W. (1987). Rehabilitation employee organizational withdrawal behavior. Rehabilitation Psychology, 32 (2), 121-124.

Ryan, R. R. (1996). A survey of occupational stress, psychological strain and coping resources in licensed professional counselors in Virginia. (Doctoral dissertation, Virginia Polytechnic Institute and State University, 1997). 
Sandu, K., \& Das, I. (1998). Effect of work culture upon stress, strain and coping strategies of managers. Journal of the Indian Academy of Applied Psychology, 24 (1-2), 15-18.

Selye, H. (1974). Stress without distress. New York: J.B. Lippincott Company.

Selye, H. (1976). The stress of life (revised ed.). New York: McGraw Hill.

Selye, H. (1983). The stress concept: Past, present, and future. In C. L. Cooper (Ed.), Stress research: Issues for the eighties (pp. 1-20). New York, NY: John Wiley \& Sons.

Selye, H. (1993). History of stress concept. In L. Goldberger \& S. Breznitz (Eds.), Handbook of stress: Theoretical and clinical aspects $\left(2^{\text {nd }}\right.$ Edition) (pp. 7-17). New York: The Free Press.

Shinn, M., Rosario, M., Morch, H., \& Chestnut, D. E. (1984). Coping with job stress and burnout in human services. Journal of Personality and Social Psychology, 46, 864-876.

Sowa, C. J., May, K. M., \& Niles, S. G. (1994). Occupational stress within the counseling profession: Implications for counselor training. Counselor Education \& Supervision, 34 (1), 1929.

SPSS, Inc. (1998). SPSS 9.0 for Windows update [Computer software]. Chicago: SPSS, Inc.

Sutherland, L. F., Fogarty, G. J., \& Pithers, R. T. (1995). Congruence as a predictor of occupational stress. Journal of Vocational Behavior, 46 (3), 292-309.

Trivette, P. S. (1993). A national survey of occupational stress, psychological strain and coping resources in elementary school counselors. (Doctoral dissertation, Virginia Polytechnic Institute and State University, 1992).

Turnipseed, D. L. (1999). An exploratory study of the hardy personality at work in the health care industry. Psychological Reports, 85 (3, Pt 2 [Special Issue]), 1199-1217.

van der Merwe, R., \& Miller, S. (1975). The measurement of labour turnover. In B. O. Pettman (Ed.), Labour turnover and retention (pp. 1-30). Epping, Essex: Gower Press Limited.

Wells, D. L. (1993). Factors affecting teachers commitment to stay in teaching: A causal model. (Doctoral dissertation, Virginia Polytechnic Institute and State University, 1993).

Winnubst, J. (1993). Organizational structure, social support, and burnout. In W. B. Schaufeli, C. Maslach, \& T. Marek, T. (Eds.), Professional burnout: Recent developments in theory and research (pp. 151-162). Washington, DC: Taylor \& Francis.

Wright, T. J., \& Emener, W. G. (1991). Rehabilitation counseling. In W. G. Emener \& M. A. Darrow (Eds.), Career Explorations in human services (pp. 230-246). Springfield, IL: Charles C. Thomas Publisher. 
APPENDIX A 


\section{$\underline{\text { Individual Data Form }}$}

This Data Form will provide information about yourself and your work setting. Please read each item and respond as indicated.

1. Your current age:

2. Gender: Female Male
3. Your ethnicity: Hispanic African American___ Caucasian Asian _ Native American __ Other (please specify)

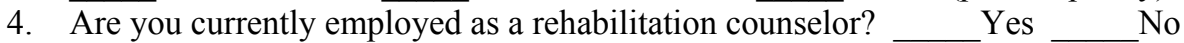

If you answered YES, please go to question \#6.

If you answered NO, please go to question \#5.

5. Why did you leave the field of rehabilitation? Lack of advancement Problems with supervisor/administrator Low pay Stress Related Problems Other (please describe)

*If you answered question \#5 you do not need to complete the rest of this information data form.

6. What is your employment status as a rehabilitation counselor? Full-Time Part-Time Other (please specify)

7. How many years have you been employed as a rehabilitation counselor? Years (Full-Time) Years (Part-Time) Other (please specify)

8. How many hours a week do you work (include all jobs you currently have)?

9. What is your present work setting? Private Non-Profit Private For-Profit Public

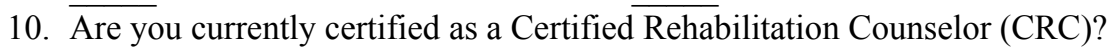
No Yes: If so, how many years have you been certified?

11. How many clients do you currently see per week?

12. What is the size of you current counseling case-load (how many clients are assigned to you)?

13. On a scale of one to ten, rank the level of your total job related stress as a counselor ( 1 is the lowest amount of stress and 10 is the highest amount)

14. Have you ever received treatment for stress related problems?

Yes No

Following are some questions about the organization for which you work. Circle one number per statement using the following scale:
$1=$ Agree
$2=$ Tend to Agree
$3=$ Tend to Disagree
$4=$ Disagree

16. I often think about quitting

$$
1234
$$

17. It is very likely that I will actively look for a new job in the next year

18. I will leave this organization in the next year ..................

19. I will leave this organization as soon as I find another job ........

20. If I leave my current job I will look for a job: In the field of rehabilitation in a different organization In another field than rehabilitation (another industry) I will not seek employment (leave workforce) Other (please specify)

THANK YOU VERY MUCH!

I really appreciate you time and effort in filling out this form. If you would like to make any comments of suggestions, please indicate them below. 


\section{$\underline{\text { Phone Follow-up }}$}

Code

1. Current Age

2. Gender Male Female

3. Current Marital Status

4. Ethnicity

5. Currently employed full-time as a rehabilitation counselor? yes no

6. If you are not employed as a rehabilitation counselor, what is your current job title and why did you leave the position of rehabilitation counselor?

\section{STOP HERE IF THEY ARE NOT A REHABILITATION COUNSELOR AND GO TO QUESTION \#14}

7. If yes, how many years have you been employed as a rehabilitation counselor?

8. Current Practice Setting?

9. Certified as a CRC? no ___ yes, if so how many years?

10. How many clients are currently on your caseload?

11. How many hours a week so you work?

12. On a scale of one to ten, rank the level of total job related stress (one being the lowest and ten being the highest)

13. On a scale of one to ten, rank the level of total non-job related stress (one being the lowest and ten being the highest)

14. I appreciate the time you took to answer these questions, and I was interested in finding out why you did not respond to the mailed survey. 
APPENDIX B 


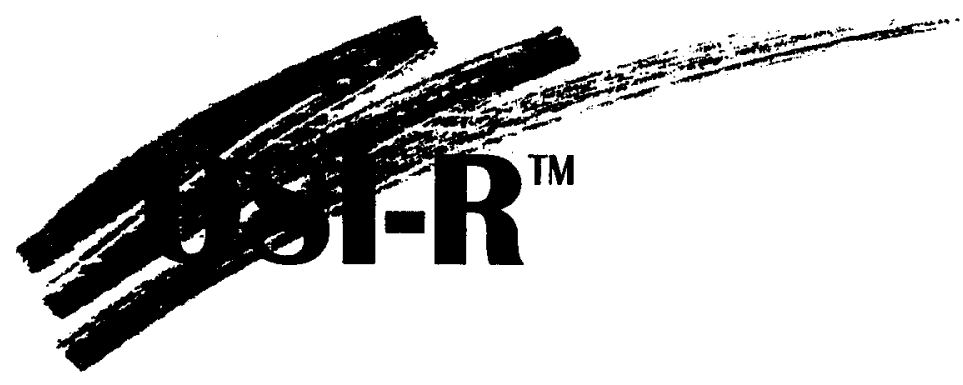

Item Booklet

This booklet is divided into three sections which contain statements about work situations and individual habits. You may be asked to complete one, two, or all three of the sections. Be sure to respond to all of the statements for each section you are asked to complete.

Begin by completing the information on the front page of your OSI-R Rating Sheet. Enter your name, age, gender, job title, and today's date. Now turn to page 3 for directions for completing your ratings. in any form or by any means without written permission of Psychological Assessment Resources, Inc. This booklet is printed in green ink on white paper. Any other version is unauthorized. 


\section{Directions}

Read each statement carefully. For each statement, fill in the circle with the number which fits you best.

Fill in (1) if the statement is rarely or never true.

Fill in (2) if the statement is occasionally true.

Fill in (3) if the statement is often true.

Fill in (4) if the statement is usually true.

Fill in (5) if the statement is true most of the time.

For example, if you believe that a statement is often true about you, you would fill in the 3 circle for that statement on your rating sheet.

\section{Example \\ 1 (1)(2) (4) (5)}

Fill in only one circle for each statement. Be sure to rate ALL of the statements for each section you are asked to complete. DO NOT ERASE!

If you need to change an answer, make an " $X$ " through the incorrect response and then fill in the correct circle, like this.

\section{Example \\ 1 (1) (4) (5)}

If a statement is not applicable, please mark (1) rarely or never true. 


\section{Make your ratings in Section One of the Rating Sheet}

1. At work I am expected to do too many different tasks in too little time.

2. I feel that my job responsibilities are increasing.

3. I am expected to perform tasks on my job for which I have never been trained.

4. I have to take work home with me.

5. I have the resources I need to get my job done.

6. I'm good at my job.

7. I work under tight time deadlines.

8. I wish that I had more help to deal with the demands placed upon me at work.

9. My job requires me to work in several equally important areas at once.

10. I am expected to do more work than is reasonable.

11. My career is progressing about as I hoped it would.

12. My job fits my skills and interests.

13. I am bored with my job.

14. I feel I have enough responsibility on my job.

15. My talents are being used on my job.

16. My job has a good future.

17. I am able to satisfy my needs for success and recognition in my job.

18. I feel overqualified for my job.

19. I learn new skills in my work.

20. I have to perform tasks that are beneath my ability.
21. My supervisor provides me with useful feedback about my performance.

22. It is clear to me what I have to do to get ahead.

23. I am uncertain about what I am supposed to accomplish in my work.

24. When faced with several tasks I know which should be done first.

25. I know where to begin a new project when it is assigned to me.

26. My supervisor asks for one thing, but really wants another.

27. I understand what is acceptable personal behavior on my job (e.g., dress, interpersonal relations, etc.)

28. The priorities of my job are clear to me.

29. I have a clear understanding of how my boss wants me to spend my time.

30. I know the basis on which I am evaluated.

31. I feel conflict between what my employer expects me to do and what I think is right or proper.

32. I feel caught between factions at work.

33. I have more than one person telling me what to do.

34. I know where I fit in my organization.

35. I feel good about the work I do.

36. My supervisors have conflicting ideas about what I should be doing.

37. My job requires working with individuals from several departments or work areas.

38. It is clear who really runs things where I work.

39. I have divided loyalties on my job.

40. I frequently disagree with individuals from other work units or departments. 
41. I deal with more people during the day than I prefer.

42. I spend time concerned with the problems others at work bring to me.

43. I am responsible for the welfare of subordinates.

44. People on-the-job look to me for leadership.

45. I have on-the-job responsibility for the activities of others.

46. I worry about whether the people who work for/with me will get things done properly.

47. My job requires me to make important decisions.

48. If I make a mistake in my work, the consequences for others can be pretty bad.

49. I worry about meeting my job responsibilities.

50. I like the people I work with.
51. On my job I am exposed to high levels of noise.

52. On my job I am exposed to high levels of wetness.

53. On my job I am exposed to high levels of dust.

54. On my job I am exposed to temperature extremes.

55. On my job I am exposed to bright light.

56. My job is physically dangerous.

57. I have an erratic work schedule.

58. I work all by myself.

59. On my job I am exposed to unpleasant odors.

60. On my job I am exposed to poisonous substances. 


\section{Make your ratings in Section Two of the Rating Sheet}

1. I don't seem to be able to get much done at work.

2. Lately, I dread going to work.

3. I am bored with my work.

4. I find myself getting behind in my work, lately.

5. I have accidents on the job of late.

6. The quality of my work is good.

7. Recently, I have been absent from work.

8. I find my work interesting and/or exciting.

9. I can concentrate on the things I need to at work.

10. I make errors or mistakes in my work.

11. Lately, I am easily irritated.

12. Lately, I have been depressed.

13. Lately, I have been feeling anxious.

14. I have been happy, lately.

15. So many thoughts run through my head at night that I have trouble falling asleep.

16. Lately, I respond badly in situations that normally wouldn't bother me.

17. I find myself complaining about little things.

18. Lately, I have been worrying.

19. I have a good sense of humor.

20. Things are going about as they should.
21. I wish I had more time to spend with close friends.

22. I often quarrel with the person closest to me.

23. I often argue with friends.

24. My spouse and I are happy together.

25. Lately, I do things by myself instead of with other people.

26. I quarrel with members of the family.

27. Lately, my relationships with people are good.

28. I find that I need time to myself to work out my problems.

29. Lately, I am worried about how others at work view me.

30. I have been withdrawing from people lately.

31. I have unplanned weight gains.

32. My eating habits are erratic.

33. I find myself drinking a lot lately.

34. Lately, I have been tired.

35. I have been feeling tense.

36. I have trouble falling and staying asleep.

37. I have aches and pains I can not explain.

38. I eat the wrong foods.

39. I feel well.

40. I have lots of energy lately. 


\section{Seym fintiree (PRQ)}

\section{Make your ratings in Section Three of the Rating Sheet}

1. When I need a vacation I take one.

2. I am able to do what I want to do in my free time.

3. On weekends I spend time doing the things I enjoy most.

4. I hardly ever watch television.

5. A lot of my free time is spent attending performances (e.g., sporting events, theater, movies, concerts, etc.)

6. I spend a lot of my free time in participant activities (e.g., sports, music, painting, woodworking, sewing, etc.)

7. I set aside time to do the things I really enjoy.

8. When I'm relaxing, I frequently think about work.

9. I spend enough time in recreational activities to satisfy my needs.

10. I spend a lot of my free time on hobbies (e.g., collections of various kinds, etc.)

11. I am careful about my diet (e.g., eating regularly, moderately, and with good nutrition in mind.)

12. I get regular physical checkups.

13. I avoid excessive use of alcohol.

14. I exercise regularly (at least 20 minutes, 3 times a week.)

15. I practice "relaxation" techniques.

16. I get the sleep I need.

17. I avoid eating or drinking things I know are unhealthy (e.g., coffee, tea, cigarettes, etc.)

18. I engage in meditation.

19. I practice deep breathing exercises a few minutes several times each day.

20. I floss my teeth regularly.
21. There is at least one person important to me who values me.

22. I have help with tasks around the house.

23. I have help with the important things that have to be done.

24. There is at least one sympathetic person with whom I can discuss my concerns.

25. There is at least one sympathetic person with whom I can discuss my work problems.

26. I feel I have at least one good friend I can count on.

27. I feel loved.

28. There is a person with whom I feel really close.

29. I have a circle of friends who value me.

30. If I need help at work, I know who to approach.

31. I am able to put my job out of my mind when I go home.

32. I feel that there are other jobs I could do besides my current one.

33. I periodically reexamine or reorganize my work style and schedule.

34. I can establish priorities for the use of my time.

35. Once they are set, I am able to stick to my priorities.

36. I have techniques to help avoid being distracted.

37. I can identify important elements of problems I encounter.

38. When faced with a problem I use a systematic approach.

39. When faced with the need to make a decision I try to think through the consequences of choices I might make.

40. I try to keep aware of important ways I behave and things I do. 
Additional copies available from:

PAR Psychological Assessment Resources, Inc.

P.0. Box 998/0dessa, Florida 33556/Toll-Free 1-800-331-TEST 
APPENDIX C 
January 9, 2001

Title, First Name, Last Name

Address \#1

Address \#2

City, State Postal Code

Dear

The field of rehabilitation counseling continues to face the dilemma of high turnover rates among its' professionals. We are writing to encourage your participation in a national study being conducted by Christina Mann, a certified rehabilitation counselor and doctoral candidate at Virginia Polytechnic Institute and State University.

This study is designed to investigate occupational stress, strain, and coping resources as they relate to turnover intentions of rehabilitation counselors. Analysis will consist of group data only, and your individual responses will be kept strictly confidential.

We urge you to assist Christina by taking about 30 minutes of your time to complete and return the materials you will be receiving in a few days. Her study will provide valuable information in studying the problem of turnover among rehabilitation counselors.

Thank you for your assistance in advancing the field through this national study.

Sincerely,

Thomas H. Hohenshil, Ph.D.

Professor, Counselor Education

Kusum Singh, Ph.D.

Professor, Educational Research 


\section{Virginia

January 18, 2001

Dear

I am currently completing my doctorate at Virginia Tech and am investigating occupational stress, strain, and coping resources as they relate to the turnover intentions of rehabilitation counselors for my dissertation. I am primarily interested in looking at why professionals leave positions as rehabilitation counselors and the subsequent relationship to stress, strain, and coping.

Your name was selected at random from a current list of members of the American Rehabilitation Counselors Association (ARCA). I am asking for the help of ARCA members across the country in collecting data about stress, strain, coping and turnover intentions in our profession.

Along with this letter is a copy of the Occupational Stress Inventory Revised Edition (OSI-R) Item Booklet, Rating Sheet, and an Individual Information Form. If you do not consider yourself to be currently employed as a rehabilitation counselor at least part-time, you do not need to complete the OSI-R, however please take the time to fill out the Individual Data Form. If you consider yourself to be currently employed as a rehabilitation counselor, I would greatly appreciate it if you would complete the OSI-R and the Individual Information Form. Please return all completed materials and the OSI-R item booklet, in the enclosed pre-paid envelope by February 6, 2001.

Your individual responses will be kept confidential and are numbered to keep materials together. Please put a note at the bottom of your answer sheet if you would like me to send you a copy of the results of the OSI-R.

Thank you, in advance, for your assistance.

Sincerely,

Christina M. Mann M.S., C.R.C.

No. 


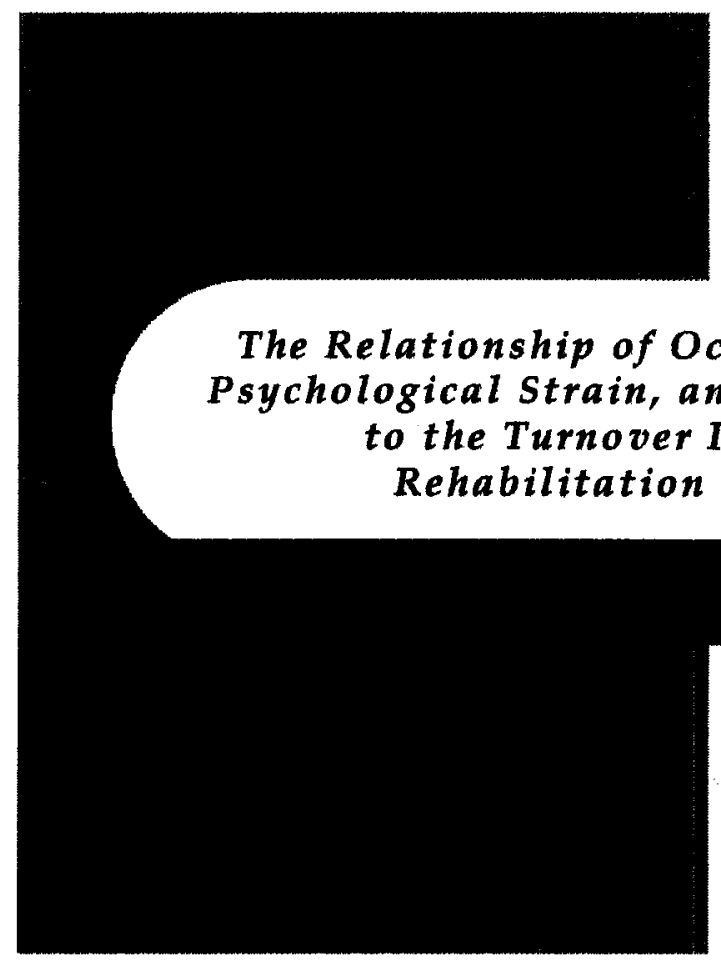

Christina M. Mann

846 Claytor Square

Blacksburg, VA 24060

A week ago I mailed you a packet of materials requesting your response regarding occupational stress and turnover in our profession.

If you have already returned your response, I would like to sincerely thank you. If not, I urge you to do so as soon as possible. Your input is extremely important in order for the results to accurately reflect the opinions of rehabilitation counselors.

If for any reason, you need a new packet, please call me collect at (540) $552-6955$ or email me at chrismann@vt.edu, and I will mail you the materials. Thank you for your support.

Sincerely, 


\section{Virginia

Christina M. Mann

846 Claytor Square

Blacksburg, VA 24060

February 15, 2001

Approximately a month ago, I wrote you asking for your input on a study involving occupational stress among rehabilitation counselors. This topic is being researched as part of my doctoral dissertation at Virginia Tech. Our records indicate that your response has not been received yet.

If you have recently responded, I would like to thank you for taking the time to participate. If you have not responded, I am again writing to encourage your participation in this important national study. In order for the results to accurately reflect the opinions of rehabilitation counselors, it is essential that all participants in the sample return the completed questionnaires. Your individual responses will remain confidential and only group scores will be reported.

I have enclosed another full packet of materials in case you have misplaced the one previously sent. Please take a few minutes from your busy schedule to complete and return the materials. If you have any questions, feel free to call me collect at (540) $552-6955$ or email me at chrismann@vt.edu.

Thanks, in advance, for your help with this research.

Sincerely,

Christina M. Mann M.S., C.R.C. 
APPENDIX D 


\section{Correlation matrix}

\begin{tabular}{|c|c|c|c|c|c|c|c|c|c|c|}
\hline Variables & 1 & 2 & 3 & 4 & 5 & 6 & 7 & 8 & 9 & 10 \\
\hline 1. Age & 1.0 & & & & & & & & & \\
\hline 2. Gender & $-.274 * *$ & 1.0 & & & & & & & & \\
\hline $\begin{array}{l}\text { 3. CRC } \\
\text { status }\end{array}$ & .110 & -.042 & 1.0 & & & & & & & \\
\hline 4.YrsExp & $.634 * *$ & $-.317 * *$ & $.251 * *$ & 1.0 & & & & & & \\
\hline $\begin{array}{l}\text { 5. \# of } \\
\text { Clients }\end{array}$ & .056 & -.012 & .052 & .117 & 1.0 & & & & & \\
\hline $\begin{array}{l}\text { 6. Hours per } \\
\text { week }\end{array}$ & .064 & $-.185^{*}$ & .088 & .094 & -.004 & 1.0 & & & & \\
\hline 7. Stress & -.005 & -.126 & -.047 & -.041 & .058 & .151 & 1.0 & & & \\
\hline 8. Coping & .079 & .049 & .093 & .045 & $-.198 *$ & -.147 & $-.357 * *$ & 1.0 & & \\
\hline 9. Strain & $-.233 * *$ & .082 & -.142 & $-.202 * *$ & .089 & .001 & $.617 * *$ & $-.550 * *$ & 1.0 & \\
\hline $\begin{array}{l}\text { 10. Turnover } \\
\text { Intention }\end{array}$ & $-.219 * *$ & -.038 & -.160 & -.165 & -.022 & -.026 & $.546^{* *}$ & $-.363 * *$ & $.519 * *$ & 1.0 \\
\hline Mean & 43.79 & & & 10.23 & 88.42 & 44.72 & 138.27 & 136.46 & 83.18 & 7.64 \\
\hline SD & 11.08 & & & 9.87 & 102.55 & 8.37 & 27 & 19.15 & 23.11 & 3.9 \\
\hline Range & $23-78$ & & & $.25-51$ & $2-700$ & $25-70$ & $77-202$ & $89-180$ & $45-145$ & $4-16$ \\
\hline
\end{tabular}




\section{Alpha Coefficients for the Occupational Stress Inventory Revised Edition (OSI-R) reported in}

the manual versus Rehabilitation Counselors (RC) sampled

Domain/Scale

Occupational Role Questionnaire (ORQ)

Role Overload (RO)

Role Insufficiency (RI)

Role Ambiguity (RA)

Role Boundary (RB)

Responsibility (R)

Physical Environment (PE)

Personal Strain Questionnaire (PSQ)

Vocational Strain (VS)

Psychological Strain (PSY)

Interpersonal Strain (IS)

Physical Strain (PHS)

Personal Resources Questionnaire (PRQ)

Recreation (RE)

Self-Care (SC)

Social Support (SS)

Rational/Cognitive (RC)
Number of Items

60

10

10

10

10

10

10

40

10

10

10

10

40

10

10

10

10
OSI-R RC

$\begin{array}{ll}.88 & .73\end{array}$

$\begin{array}{ll}.78 & .83\end{array}$

$\begin{array}{ll}.85 & .83\end{array}$

$\begin{array}{ll}.79 & .75\end{array}$

$\begin{array}{ll}.72 & .82\end{array}$

$\begin{array}{ll}.75 & .62\end{array}$

$\begin{array}{ll}.89 & .69\end{array}$

$\begin{array}{ll}.93 & .89\end{array}$

$\begin{array}{ll}.75 & .81\end{array}$

$\begin{array}{ll}.86 & .85\end{array}$

$\begin{array}{ll}.75 & .72\end{array}$

$\begin{array}{ll}.85 & .87\end{array}$

$\begin{array}{ll}.89 & .62\end{array}$

$.77 \quad .84$

$\begin{array}{ll}.70 & .72\end{array}$

$\begin{array}{ll}.88 & .87\end{array}$

$\begin{array}{ll}.81 & .74\end{array}$ 


\author{
Christina Mann Layne \\ Maiden Name: Christina Marie Mann
}

\title{
EDUCATION
}

\author{
VIRGINIA POLYTECHNIC INSTITUTE AND STATE UNIVERSITY, Blacksburg, VA \\ Doctor of Philosophy \\ Major: \\ October 2001 \\ GPA: \\ Counselor Education \\ 3.83
}

UNIVERSITY AT ALBANY, STATE UNIVERSITY OF NEW YORK, Albany, NY

Masters of Science

December 1998

Major:

Rehabilitation Counseling Psychology

GPA:

3.92

HUDSON VALLEY COMMUNITY COLLEGE, Troy, NY

Psychology Pre-requisites

GPA:

Fall Semester 1996, Spring Semester 1997

4.0

\author{
VIRGINIA POLYTECHNIC INSTITUTE AND STATE UNIVERSITY, Blacksburg, VA \\ Bachalate of Science \\ Major: \\ GPA: \\ May 1995 \\ Housing, Interior Design, \& Resource Mgmt \\ 3.54
}

\section{HONORS}

Robert and Margaret Hoppock Scholarship, Virginia Tech (2001)

McComas-Chambless Scholarship, Virginia Tech (2001)

Chi sigma Iota, Counseling Academic \& Professional Honor Society,Virginia Tech(2000-01)

Recreational Sports Student Leader of the Year, Virginia Tech. (1995)

Wilton Company Leadership Scholar, Virginia Tech. (1994)

Gamma Beta Phi National Honor Society, Virginia Tech. (1993 - 1995)

Phi Upsilon Omicron National Honor Society, Virginia Tech. (1992 - 1995)

\section{PROFESSIONAL ASSOCIATIONS}

American Counseling Association (ACA)

New River Valley Counselors Association (NVRCA)

Southern Association for Counselor Educators and Supervisors (SACES)

Virginia Counselors Association (VCA)

Virginia Counseling Graduate Students (VCGSA)

American Rehabilitation Counselor Association (ARCA)

\section{CLINICAL EXPERIENCE}

10/01- present NEW RIVER VALLEY COMMUNITY SERVICE BOARD, Blacksburg, VA

\section{Community Living Clinician}

Provide mental health supports and crisis stabilization to severely mentally ill adults living in the community. Assessment of mental status to determine if clients are psychiatrically stable. Assist clients in achieving their individual service plan goals through access to the community and medication management. Work on independent living including vocational and leisure activities, as well as ADL's. Collaborate with mental health professionals and provide a liaison to friends and family members.

05/01- present NEW RIVER VALLEY COMMUNITY SERVICE BOARD, Blacksburg, VA Host Home Provider

Provide residential living supervision for an individual diagnosed with PDD, NOS. Work on goals towards independent living including vocational and leisure activities, as well as ADL's. Collaborate with mental health professionals and provide a liaison to biological family members. 
04/01 - 10/01 CHILD \& FAMILY SERVICES, OUTPATIENT COUNSELING, Roanoke, VA

Assessment Therapist

Complete diagnostic evaluations for children and adolescents in Roanoke County and surrounding areas. Recommend appropriate therapeutic services and treatment plans. Collaborate with staff psychiatrist and clinicians, as well as various local mental health professionals.

08/00 - 05/01 APPLIED BEHAVIOR ANALYSIS INTERVENTION PROGRAM, Blacksburg, VA Senior Therapist and Trainer

Designed and developed an intensive home-based A.B.A. program for a two year old diagnosed at 18 months with Autism. Responsible for training and supervising behavior therapists in the practices of A.B.A. and behavioral methods. Responsible for implementing and facilitating weekly staff meetings. Consult with Clinical Psychologist on programs for discrete trial training, maintenance, and generalization as well as incidental learning.

5/00 - 05/01 NEW RIVER VALLEY COMMUNITY SERVICE BOARD, Blacksburg, VA Community Service Provider

Provide residential counseling to adults with developmental disabilities and comorbid diagnoses (e.g. schizophrenia, obsessive-compulsive disorder, attention-deficit hyperactivity disorder, and pica) as well as adults with psychiatric disorders. Settings vary from private residences to group homes. Responsibilities include charting daily progress notes, participating in case conceptualization, assisting individuals in achieving daily living skills, and community integration. Certified to administer medication. Participate in supervision and site trainings.

01/00 - 05/00 COOK COUNSELING CENTER - VIRGINIA TECH, Blacksburg, VA

Counseling Intern: Total supervised hours: 200

Provided group and individual counseling to undergraduate and graduate student attending Virginia Polytechnic Institute and State University. Co-facilitated group therapy for students mandated by the university judicial affairs board with a focus on issues with alcohol. Provided referrals to community mental health care professionals, as well as university psychiatrists, dieticians, physicians, and other school personnel. Participated in weekly group and individual supervision sessions, as well as weekly staff development meetings. Administered the following assessments: Beck Depression Inventory (BDI), Beck Anxiety Inventory (BAI), Eating Disorders Inventory (EDI-2), Strong Interest Inventory (SII), Myers-Briggs Type Indicator (MBTI), StateTrait Anxiety Inventory (STAI), and the Personality Assessment Inventory (PAI).

Spring 2000 NATIONAL EATING DISORDERS SCREENING DAY, Blacksburg, VA Administered the Eating Disorders Inventory (EDI-2) to college students at Virginia Tech. Responsible for providing appropriate referrals to campus and community agencies.

08/98 - 01/99 FULTON-MONTGOMERY COMMUNITY COLLEGE, Johnstown, NY Counseling Intern: Total supervised hours: 300

Acted as Interim Coordinator of Services for Students with Disabilities. Determined and arranged appropriate accommodations for thirty-five students with documented disabilities. Provided personal, academic, and vocational counseling. Provided advocacy and support, by making referrals to campus and community agencies/groups when appropriate. Provided information and guidance to the administration on compliance with the Americans with Disabilities Act. Participated in weekly supervisory meetings, as well as monthly faculty meetings.

10/96 - 12/99 ALBANY COUNTY ASSOCIATION FOR RETARDED CITIZENS, Albany, NY Resident Counselor: Total supervised hours: 2293

Provided counseling to adults with developmental disabilities and comorbid diagnoses (e.g., schizophrenia, obsessive-compulsive disorder, attention-deficit hyperactivity disorder, and pica). Responsibilities included writing daily progress notes, participating in case conceptualizations, and charting behavior progress notes. Administered medications and assisted individuals in achieving ADL's. 
08/96 - 08/98 APPLIED BEHAVIOR ANALYSIS, INTERVENTION PROGRAM, Delmar, NY

Behavior Therapist: Total supervised hours: 779

Supervised by a licensed Ph.D. psychologist and Ph.D. speech pathologist. Provided assessment and long-term therapy to a child diagnosed with autism. Worked in collaboration with Norrell

Health Care Services and Village Preschool as a certified personal care aide and one-to-one aide.

Provided therapy in the areas of sensory integration, daily living skills, play therapy, discrete trial training, community generalization, speech and auditory training. Collected and graphed data for analysis. Participated in weekly supervisory meetings.

01/98 - 08/98 GLENMONT JOB CORP., Glenmont, NY

Counseling Intern: Total supervised hours: 510

Provided multicultural counseling to adolescents in a federally funded program that offered academic and vocational training to youth ages sixteen to twenty-four. Responsibilities included individual counseling with a special population comprised of youth transported and recruited from various shelters in New York city. Developed and co-facilitated various group therapy programs targeting new students, within the general population, and their transitioning as well as coping processes. Participated in weekly supervisory meetings.

\section{TEACHING EXPERIENCE}

05/00 - 09/00 VIRGINIA POLYTECHNIC INSTITUTE \& STATE UNIVERSITY, Blacksburg, VA Teaching Intern: Total Supervised Hours: 400

Courses: Career Development and Information Services (on-line)

http://www.chre.vt.edu/thohen/career4.htm

Responsible for assisting with two masters level on-line courses aimed toward facilitating student's understanding of career development and related topics. Responsibilities included review and evaluation of student's assignments related to site visits, article reviews, computer assessments, internet searches, and website evaluations.

08/00 - 12/00 VIRGINIA POLYTECHNIC INSTITUTE \& STATE UNIVERSITY, Blacksburg, VA Teaching Intern: Total Supervised Hours Expected: 200

Course: Diagnostic and Statistical Manual of Mental Disorders, Fourth Edition DSM-IV http://www.chre.vt.edu/thohen/dsm.htm.

Responsible for assisting with a masters/doctoral level course focused on the study of both normal and abnormal behavior, with special emphasis upon the identification and assessment of mental disorders. Responsibilities included developing weekly lectures, cases studies, and power point presentations. Additional responsibilities included reviewing instructional materials as well as evaluation of assignments, quizzes, and tests.

08/00 - 12/00 VIRGINIA POLYTECHNIC INSTITUTE \& STATE UNIVERSITY, Blacksburg, VA Teaching Intern

Course: Orientation to Professional Counseling

http://www.chre.vt.edu/thohen/orientation/htm.

Responsible for assisting with a masters level course focused on providing students with an overview of the counseling profession, including employment settings and services normally provided. An examination regarding the objectives, practices, and evaluative techniques in the counseling of children and adults is also provided, as well as a basis for understanding the ethics, philosophy, and purposes of the counseling profession.

\section{RESEARCH EXPERIENCE}

08/00 - 05/01 VIRGINIA POLYTECHNIC INSTITUTE \& STATE UNIVERSITY, Blacksburg, VA Graduate Assistant

Assisted faculty members of the Counselor Education Department with any pending projects. Responsibilities included multicultural recruiting for the program through outreach and conference presentations. Attended program area meetings and assisted in various administrative tasks. Provided supervision to masters level students at the Roanoke Graduate Center. Collaborated with 
a faculty member to develop articles for publication and analyze research.

07/99 - 08/00 VIRGINIA VIEW, Blacksburg, VA

Graduate Assistant

http://www.vaview.vt.edu/

Provided occupational and educational information primarily to the residents of Virginia, as well as to out-of-state individuals and programs upon request. Responsibilities included providing answers to career information questions, locating and providing referrals to other agencies, responding to on-line questions, and researching career information for accuracy and applicability. Additional responsibilities included developing disability resources and accommodations for counselors and educators for use with Virginia VIEW's Interactive View computer software, as well as for on-line users throughout the country and internationally.

06/97 - 05/99 UNIVERSITY AT ALBANY, STATE UNIVERSITY OF NEW YORK, Albany, NY Senior Research Assistant

Worked under the supervision of V. Mark Durand, Ph.D., and graduate research assistants. Served as a rater of quantitative data for a study on preventing severe behavior problems in children (primarily children with pervasive developmental disabilities). Met regularly with graduate assistants to enhance interrater reliability and interpret measures. Conducted home visits with families to collect assessment measures. Administered and rated the following assessments: The Motivational Assessment Scale (I \& II), The Child Behavior Checklist, The Toddler Temperament Scale, Locke-Wallace Marital Adjustment Test, Beck Depression Inventory, Family Environment Scale, Questionnaire on Resources and Stress, The Vineland Adaptive Behavior Scales, and the Scales of Independent Behavior.

\section{PRESENTATIONS}

10/01 VIRGINIA POLYTECHNIC INSTITUTE \& STATE UNIVERSITY

Guest Lecturer

"Applied Behavioral Analysis and its Relationship to Behavior Therapy"

$09 / 01$

\section{BLUERIDGE BEHAVIORAL HEALTHCARECHILD \& FAMILY OUTPATIENT} SERVICES

Staff In-service Trainer

"Counseling children and adolescents with Aspergers Syndrome"

09/01 VIRGINIA POLYTECHNIC INSTITUTE \& STATE UNIVERSITY

Guest Lecturer - Orientation to Professional Counseling course

"Introduction to Rehabilitation Counseling" and "Intake and Assessment"

04/01 VIRGINIA SCHOOL COUNSELORS ASSOCIATION ANNUAL CONFERENCE Co-presenter

"Sexuality and Developmental Disabilities in the Schools"

11/00 VIRGINIA COUNSELORS ASSOCIATION ANNUAL CONFERENCE

Presenter

"Our Invisible Children" - Siblings of children with developmental disabilities

$10 / 00$

SOUTHERN ASSOCIATION FOR COUNSELOR EDUCATORS \& SUPERVISORS - ANNUAL CONFERENCE (SACES)

Co-Presenter: Christina Mann, Dr. Hildy Getz, \& Dr. Claire Cole Vaught

"Using Technology in Counselor Education" 
$04 / 00$

COLLEGE OF HUMAN RESOURCES GRADUATE RESEARCH DAY

Presenter

"Siblings of children diagnosed with autism: Literature review and implications for

counselors"

03/00 NEW RIVER VALLEY COMMUNITY SERVICE BOARD

Staff Training Workshop Presenter

"Service Care Providers and Autism: How to be an Effective Caregiver"

$09 / 99$

NORTH CAROLINA ASSOCIATION OF COUNSELOR EDUCATORS \& SUPERVISORS

Interactive Television (VTEL) Demonstration

"Clinical Supervision Course via Interactive Television"

$04 / 98$

NORRELL HEALTH CARE SERVICES

Staff Training Seminar

"Childhood disorders: An overview for personal care and home health aides"

$02 / 98$

THE NEW YORK STATE ASSOCIATION OF BEHAVIOR ANALYSIS, ANNUAL CONFERENCE October 15, 1998

Poster Presentation: conducted and presented findings of experimental research study

"The Influence of Hemisync Music on Learning and Self-Stimulatory Behaviors in

Children with Autism"

PUBLICATIONS \& MANUSCRIPTS

Mann, C.M. (in review). Siblings of children diagnosed with autism: Implications for counselors. The Journal of Autism and Developmental Disorders.

Mann, C.M., \& Hohenshil, T.H. (in press ). Graduate students view the advantages and disadvantages of using the Internet for career development programs. Journal of Career Planning and Adult Development.

\section{TECHNOLOGY COMPETENCIES}

Distance Education: Instruction via Interactive Television (VTEL), Internet Instruction, Email

Other: Microsoft Power Point, Microsoft Excel, Word Perfect, Microsoft Word

\section{ADMINISTRATIVE EXPERIENCE}

05/94 - 08/96 REGENCY WINDSOR MANAGEMENT COMPANIES, -

Property Manager

Interned at thirteen property sites from 05/94 - 01/95. Worked at four sites in the following roles: manager trainee, assistant manager, and property manager. Responsible for public relations, community outreach, leasing, marketing, maintenance, budgets, hiring, and court procedures. Developed budgets and presented them for review by executive board members. Worked closely with company lawyers to file suits, handle employee/resident complaints, and maintain building codes. Coordinated local public library project to renovate building spaces and increase revenue.

11/91 - 05/95 VIRGINIA POLYTECHNIC INSTITUTE \& STATE UNIVERSITY, Blacksburg, VA Life Guard Manager, Assistant Manager, Lifeguard, Swim Instructor

Supervised twenty-one lifeguards annually during daily shifts at the University aquatic facility. Met weekly with supervisor to coordinate semester programs, schedules, and special events. Hired and trained new team members in accordance with federal and state laws. Served as a committee member on a board to develop the design of a new aquatic facility to be built on campus. Served as the student committee member for department meetings. Worked with supervisor and department heads on annual budget proposals. 


\section{ACTIVITIES}

New River Valley Counselors Association, President-Elect, Virginia (5/01- present)

Chi Sigma Iota, Treasurer, Virginia Tech. (5/00-5/01)

Graduate Student Assembly, Department Representative, Virginia Tech. (9/99-9/00)

Dept. of Recreational Sports, Student Roundtable Member, Virginia Tech. (1994-1995)

Gamma Beta Phi, Historian, Virginia Tech. (1993-1994)

University Fitness Organization, Treasurer, Virginia Tech. (1993-1994) 